\title{
Functions of the Lentiviral Accessory Protein Nef During the Distinct Steps of HIV and SIV Replication Cycle
}

\author{
Luciana J. Costa, Luiza M. Mendonça and Thatiane L. Sampaio \\ Departamento de Virologia, Instituto de Microbiologia Paulo de Góes, \\ Universidade Federal do Rio de Janeiro \\ Brazil
}

\section{Introduction}

Human and Simian Immunodeficiency Viruses (HIV and SIV) are the etiological agents of the Acquired Immunodeficiency Syndrome (AIDS) in humans and the Simian AIDS (SAIDS) in macaques, respectively. HIVs and SIVs are members of the Retroviridae family, Lentivirus genera, and are considered complex retroviruses since its genome organization predicts the presence of at least 6 open reading frames (ORFs) in addition to the main Gag, Pol and Env ORFs present in the genomes of all retroviruses. These additional ORFs code for both regulatory (Tat and Rev) and accessory (Nef, Vif, Vpr, Vpu and Vpx) viral proteins and are all organized from the $5^{\prime}$ half of the genome in a way that overlap both with each other and with the Pol and Env ORFs and the non-coding 3' Long Terminal Repeat (LTR) region (Figure 1). To ensure its expression and to achieve an optimal production of the viral progeny, complex mechanisms have evolved in these viruses that tightly control the expression of these ORFs during the viral replication cycle. The existence of such a number of viral proteins in addition to the viral structural (Gag and Env) and enzymatic (Pol) proteins allows the virus to explore new mechanisms to control the different steps of the replication cycle and to avoid the host cell defense. In this chapter we shall review the different steps of the HIV and SIV replication cycle with emphasis in the role taken by the viral accessory protein Nef, in both subverting the host cell machinery and influencing the function and activation of viral structural and enzymatic proteins in order to optimize viral progeny production as well as in evading the host cell defenses.

Lentiviral accessory proteins Vif, Vpr, Vpu and Nef were classically regarded as nonessential for virus production and/or infectivity since laboratory adapted HIV strains lacking the expression of these proteins could still replicate to several levels (Adachi et al., 1991). Since then, several studies demonstrated the crucial importance of these proteins to the efficient replication, infectivity and spread of both HIV and SIV (Kirchhoff, 2010).

Vif (Aguiar and Peterlin, 2008) and Vpu (Adachi et al., 1991) have now been acknowledged as crucial viral factors that counteract the host cell innate defense. Vif interacts and prompts the degradation of a family of cytidine deaminases DNA/RNA editing enzymes, known as Apoliprotein B mRNA-editing Enzymes (APOBECs), that otherwise would inhibit HIV and SIV replication by causing hypermutation of nascent 
retroviral genomes by deamination of cytidine residues (Aguiar and Peterlin, 2008). Vpu is a type- 1 membrane associated protein that was first demonstrated to be involved in the downmodulation of the Cluster of Differentiation Antigen 4 (CD4) receptor from the infected cell surface by a mechanism of inducing the proteassomal degradation of the newly synthesized CD4 molecules in the Endoplasmic Reticulum (ER) (Schubert et al., 1998; Willey et al., 1992). Expression of Vpu is restricted to HIV-1 and a subset of SIV linages related to HIV-1. In HIV-2 and the related SIVsooty mangabey (SIVsm) linage, which lack the $v p u$ gene, the cytoplasmic domain of the viral envelope protein gp41 mimicks this function of Vpu (Bour et al., 1996). For a long time it was considered to be the mechanism by which Vpu lead to an increase in HIV infectivity. Recently, however, it was demonstrated that Vpu in HIV-1 and related SIVs increases viral particle release from the infected cells by removing an Interferon-regulated protein (BST-2 or Theterin) from the surface of the infected cells, that otherwise would function as a host restriction factor inhibiting viral release (Neil et al., 2006; Neil et al., 2007; Neil et al., 2008).

Nef, the misnamed Negative Factor, is a myristoylated 27-35 kDa protein encoded at the far 3 'end of the primate lentiviral genome (Figure 1). Nef is post-translationally modified by the addition of a myristic acid at glycine residue at amino acid position 2 (G2) on the N-terminal of the protein. This modification is required for the association of Nef to cellular membranes. Another post-translational modification in Nef is its cleavage by the virally encoded Protease (PR), which will be discussed further. The terciary structure of the Nef protein predicts an anchor domain encompassing the first 57 amino acids from the Nterminal, a highly structured central core domain encompassing amino acid residues 58-147, and a unstructures flexible C-terminal domain encompassing amino acid residues 148-180 which is commonly named C-terminal flexible-loop (Geyer et al., 2001)

Nef was first described as a negative regulator of the HIV-1 replication since in the absence of its expression levels of transcription from the viral LTR and viral replication were reported to be higher than in cells infected with the Nef positive virus counterpart (Ahmad and Venkatesan, 1988; Cheng-Mayer et al., 1989). Soon it was demonstrated that in fact the absence of Nef expression has a negative effect for virus spread in HIV-1-infected CD4 (+) cell cultures (Cheng-Mayer et al., 1989; Hammes et al., 1989; Kim et al., 1989; Lama et al., 1999; Ross et al., 1999). Moreover, evidences accumulated that the lack of Nef expression even in CD4 (-) cell cultures leads to reduction in the infectivity of the viral progeny (Chowers et al., 1995; Goldsmith et al., 1995). The effect of the Nef protein in virus infectivity is direct and specific since it can be rescued by providing Nef in trans to the virus producer cell (Miller et al., 1995; Pandori et al., 1996). The increase in virus infectivity by Nef is wellconserved amonsgst alleles from both HIVs and SIVs and can vary from 4-40-fold increase depending on the nef allele and the cell system being assayed. Nowdays, the increase in viral infectivity by Nef is the only consensus phenotype recognized for this primate lentiviral accessory protein.

The definitive proof of the crucial importance of Nef for HIV and SIV infections came from studies demonstrating that the disruption or the absence of the nef gene in both viruses was related to a slower or non-progression to AIDS in naturally infected humans and experimentally infected rhesus macaques, respectively (Daniel et al., 1992; Deacon et al., 1995; Kirchhoff et al., 1995). It was clearly demonstrated in these studies that in the absence of Nef expression infection with these viruses failed to mantain high levels of viremia and to progress to AIDS, defining Nef as a key factor for the pathogenesis of primate lentiviruses. 
As soon as it was demonstrated that Nef has an important role for HIV and SIV infections several studies were conducted to ellucidate the mechanism by which this protein influences viral replication. The several functions described for Nef in the last two decades are reviewed in the sections bellow.

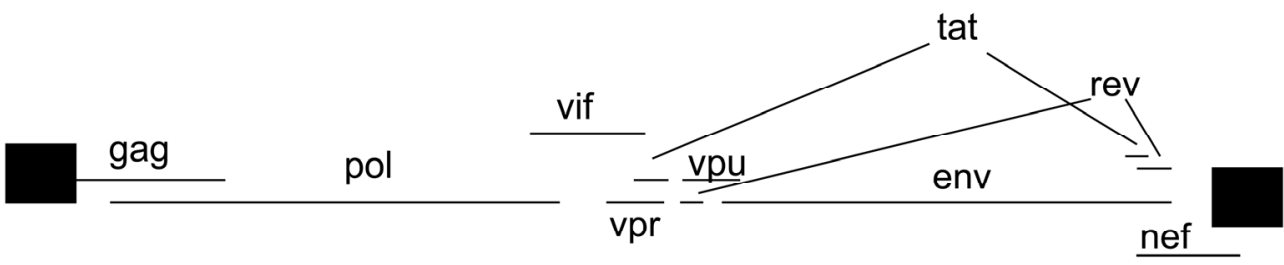

Fig. 1. Representative genomic organization of the provirus of the primate lentiviruses. The main (gag, pol and env); regulatory (tat and rev); and accessory (vif, vpr, vpu and nef) ORFs are represented by horizontal lines. The black squares represent the LTRs present at the 5'and 3' extremities of the genome. The two exons of tat and rev are conected by angled lines. Note the extensive overlap of the structural, regulatory and accessory ORFs from the 3 'half of the genome.

\section{The classical functions of the HIV and SIV Nef proteins}

\subsection{Downmodulation of CD4 and MHC-I}

The Nef protein from HIV and SIV have multiple functions and achieve its biochemical effects upon interactions with cellular components. Over thirty putative Nef targets have already been described. One of the first proteins that have been found associated with Nef is the human transmembrane CD4, which is downregulated from the cell surface by Nef (Garcia and Miller, 1991). Moreover, Nef also down-regulates other cell-surface proteins, as the major histocompatibility complex class I (MHC-I) molecules (Greenberg et al., 1998b; Swigut et al., 2000).

Observations from naturally HIV-1-infected individuals indicated that Nef functions on downmodulation of CD4 and MHC-I could be related to the pathogenesis of AIDS (Carl et al., 2001; Tobiume et al., 2002), however the real contribution of these functions still needs to be demonstrated (Crotti et al., 2006). The motifs in Nef that mediate CD4 downregulation were considered critical for SIVmac replication in rhesus macaques, however MHC-I downregulation by Nef is not sufficient for optimal virulence of SIVmac early in infection (Iafrate et al., 2000; Lang et al., 1997; Schindler et al., 2004). Moreover, the solely importance of the CD4 downmodulation for SIVmac pathogenesis in experimental models has been challenged (Jesus da Costa et al., 2009). The mechanisms by which Nef interferes with CD4 and MHC-I expression are described below.

CD4 is a type I integral membrane glycoprotein expressed primarily on T cells, thymocytes, and cells of the macrophage-monocyte lineage (Littman, 1987). CD4 is required for T-cell activation by the TCR signaling pathway and serves as the primary receptor for HIV and SIV. However, its continuous presence on the surface of HIV/SIV infected cell after viral entry is problematic for several reasons. First, because of their capacity to form complexes, co-expression of CD4 and the viral envelope protein gp120 disrupts the trafficking of both proteins (Lama et al., 1999; Ross et al., 1999). In addition, the presence of CD4 on the cell membrane reduces the ability of the newly formed particles to be properly released from the 
infected cell therefore reducing viral infectivity (Cortes et al., 2002; Lama et al., 1999). Finally, decreasing the number of viral receptors on the surface of an infected cell seems to prevent reinfection by HIV/SIV particles (the so-called superinfection) (Le Guern and Levy, 1992; Michel et al., 2005).

Nef reduces the steady-state levels of CD4 by several proposed models based on a premise: Nef binds to the cytoplasmatic tail and promotes the endocytosis of CD4 from the cell surface, which in turn results in CD4 degradation in lysosomes. Thus myristoylation of Nef, which is necessary for its membrane localization, is crucial for the downmodulation of CD4 (Bentham et al., 2003). For binding, a cluster of residues in the N-terminal half of HIV-1 Nef recognizes a dileucine motif within the cytoplasmatic tail of CD4 (Leu-413-414) exposed only when the serine residues in CD4 are phosphorylated (Aiken et al., 1994; Bentham et al., 2003; Pitcher et al., 1999). Subsequently, Nef acts as connector between mature CD4 and components of clathrin-dependent trafficking pathways at the cell surface (and to a lesser degree in the Golgi apparatus). For this purpose, Nef bridges the CD4 cytoplasmic tail with the adaptor protein complex of endosomal clathrin-coated pits (CCPs), thereby triggering the formation of CD4-specific endocytic vesicles, and the catalytic unit of the vacuolar proton pump v-ATPase (Bresnahan et al., 1998; Foti et al., 1997; Lu et al., 1998; Mandic et al., 2001; Mangasarian et al., 1997; Piguet et al., 1998). Furthermore, to target CD4 for lysosomal degradation Nef connects the receptor with the $\beta$ subunit of the COP-I coatomer in endosomes, diverting Nef-bound CD4 molecules from a recycling to a degradation pathway (Piguet et al., 1999).

Another conserved function of Nef across HIV/SIV is the disruption of the transport of MHC-I to the cell surface in infected $\mathrm{T}$ cells to avoid immune recognition by cytotoxic $\mathrm{T}$ lymphocytes (CTLs) (Greenberg et al., 1998b; Swigut et al., 2000). The pathway is initiated by Nef binding to the phosphorin acidic cluster sorting protein-2 (PACS-2), which controls the endosome-to-Golgi trafficking of cytosolic sorting proteins, then targeting Nef and its cargo to the perinuclear region to bind and activate Scr family kinase (SFK). This Nef-SFK complex then phosphorylates ZAP-70 (Syk in monocytes and heterologous cells) on tyrosine, enabling ZAP-70-SFK complex to bind the SH2 domain of Phosphatidyl Inositol 3 Kinase (PI3K) (Swann et al., 2001). MHC-I is constitutively internalized and recycled via a GTPase ADP ribosylation factor 6 (ARF6) pathway. This multi-kinase complex triggers internalization of cell-surface MHC-I through a clathrin-independent, ARF6-dependent pathway, which connects vesicle trafficking with actin cytoskeletal rearrangement (Atkins et al., 2008; Blagoveshchenskaya et al., 2002; Hung et al., 2007).

Other authors showed evidence that Nef acts early in the secretory pathway to redirect MHC-I from the trans-Golgi network (TGN) to the endolysosomal pathway known as anteretrograde trafficking. Nef directs the MHC-I into the trans-Golgi compartment through association with clathrin adaptor protein complex (AP-1), thereby sorting these proteins into specific clathrin-coated transport vesicles addressed to the endolysosomal pathway (Greenberg et al., 1998b), moreover MHC-I molecules in the trans-Golgi are probably targeted for degradation. Consistent with this model, RNA interference (RNAi) against AP-1 blocks Nef-mediated disruption of MHC-1. AP-1 was also demonstrated to co-precipitate with MHC-I and Nef in HIV-infected primary T cells (Roeth et al., 2004). Therefore, Nef binds to the MHC-I and stabilizes the interaction of a tyrosine in the cytoplasmic tail of MHC-I with the natural tyrosine-binding pocket in AP-1 (Wonderlich et al., 2008). Nef targets early types of MHC-I molecules in the ER by preferentially binding 
hypophosphorylated cytoplasmic tails, thus preventing completion of the secretory pathway that would finally provide an antigen-presenting receptor on the cell surface to activate killing of the virus-infected cell (Kasper et al., 2005).

These models may not be mutually exclusive, a recent work shows that Nef simultaneously uses both antiretrograde and retrograde trafficking to down-regulate human leukocyte antigen class I (HLA-I) in the peripheral blood mononuclear cells and HeLa cells (Yi et al., 2010). Besides, another report used a small molecule to disrupt Nef-SFK binding and found that Nef orchestrates a highly regulated molecular program consisting of sequential use of signaling followed by stoichiometric modes to evade immune surveillance (Dikeakos et al., 2010).

Human MHC-I main function is to regulate the development of an immune response. HLAI genes include HLA-A, B, and C (Tripathi and Agrawal, 2007) and its removal from the cell surface increases the potential susceptibility of infected cells to elimination by natural killer cells (NK). Nef downregulates highly polymorphic HLA-A and -B molecules as a mechanism of HIV-1 immune evasion, but not HLA-C or -E molecules which frequently serve as ligands to inhibit the activation of NK cells (Lanier, 2005). This selection is broadly conserved between SIV (smm/mac) and HIV-2 Nef alleles (DeGottardi et al., 2008). Moreover, differences in HLA downmodulation by Nef are based on amino acid modifications in HLA cytoplasmic domains, which implies that diverse properties of Nef are required to achieve the simultaneous evasion of the CTL and natural killer cell surveillance by HIV (DeGottardi et al., 2008; Lanier, 2005).

Nef is sufficiently adaptable to maintain downregulation of MHC-I and CD4 as a two independent functions and neither activity is optimized by the transmission event, despite the changing in immune pressure associated with sexual transmission (Noviello et al., 2007). In conclusion, the dramatic reduction of CD4 and MHCI expression in infected cells achieved by Nef seems to be in some degree important for the successful establishment of infection in a new host.

\subsection{Downmodulation of MHC-II}

In many ways Nef act in order to disrupt immune communication. Besides downmodulating MHC-I, CD80 and CD86, (Chaudhry et al., 2005; Greenberg et al., 1998a), Nef also interfere with MHC-II surface expression. However, for this surface marker, downmodulation is achieved by many mechanisms: i) Nef causes endocytosis of mature peptide-loaded MHC-II from the cell surface; ii) Nef can induce accumulation of immature MHC-II associated with the invariant chain (Ii) on the cell surface; iii) Nef reduces the rate of MHC-II delivery to the cell surface (Chaudhry et al., 2009; Stumptner-Cuvelette et al., 2001). MHC-II depends extensively on the endocytic machinery in order to be properly mounted on the cell surface. After its translocation to the endoplasmatic reticulum a mechanism is needed in order to prevent association with its own peptides. This is achieved by MHC-II association with the Ii, which blocks the MHC-II peptide cleft, forming the immature MHCII complex. This immature MHC-II complex exits the ER and move through the Golgi apparatus. Finally, vesicles containing immature MHC-II fuse to MIIC vesicles, a specialized MHC-II peptide-loading compartment containing all the components needed to Ii degradation and foreign peptide loading onto the MHC-II cleft. The mature MHC-II is then directed to the cell membrane where interaction with the TCR of a CD4+ cell can happen. A fraction of immature MHC-II travels to the plasma membrane and is subsequently 
internalized and directed to MIIC vesicles. A similar endocytosis mechanism was described to recycle mature MHC-II from the cell surface (Reid and Watts, 1992).

Nef selectively distinguishes between mature and immature MHC-II. While induces a twofold reduction of peptide-loaded MHC-II from the cell surface, Nef induces a 15-fold more accumulation of immature MHC-II complexes composed of Ii, alpha and beta MHC-II chains. The motifs in Nef needed for one function or another are different. While for mature MHC-II endocytosis, the acidic motif EEEE65 is important, for upregulation of immature MHC-II WL57,58 motif is required. For both of them the poliproline (PxxP) and dileucine (LL164) motifs in Nef are required. The amount of Nef needed also vary depending on the phenomena. It was observed in transient expression experiments that even small quantities of Nef were enough for Ii upregulation, while for MHC-II downmodulation high expression of Nef was required. Of note, those high levels of Nef expression were considered physiologically relevant, as experiments using HIV infected cells showed quantities of Nef similar to that seen on super expression experiments (Stumptner-Cuvelette et al., 2001).

Nef also acts slowing the delivery rate of newly synthesized MHC-II molecules to the plasma membrane, however this molecular mechanism is less explored (Chaudhry et al., 2009).

Loss of cell surface MHC-II induced by Nef is observed during HIV-1 host cell infection. In the presence of Nef, mature MHC-II are found at high levels in intracellular lysossomal compartments, marked with Lamp-1, while delivery of immature MHC-II to the endolysossomal compartment is impaired. MHC-II Nef-mediated endocytosis was described as dependent on Rab5, Lyst, cholesterol and Phosphatidyl Inositol Kinases, and dispenses Dynamin 2 (Dyn2) (Chaudhry et al., 2009).

This downmodulation of mature and upregulation of immature MHC-II is a function conserved in many nef alleles from HIV-1/2 and SIVs. Contrary to what is seen in MHCI downmodulation, Nef activity on MHC-II and Ii do not change significantly during the stages of infection. Of note, the strong li upregulation observed in the presence of wild type Nef is lost in some nef alleles derived from Long-term infected HIV-1 patients which do not progress to AIDS, suggesting that this feature of Nef may contribute to immune evasion (Schindler et al., 2003).

Although Nef has been described to directly bind to the citoplasmatic tail of many receptors that it modulates (Chaudhry et al., 2005), there is still no evidence that it can bind MHC-II, suggesting that Nef might interact with proteins involved in the physiological turnover pathways of this surface marker, disrupting the natural balance of MHC-II surface expression. The model postulates that recycling MHC-II enters sorting endossomes for a decision on whether they will be recycled back to surface or not, which is where Nef intervene and reroute them to the Golgi apparatus. This model takes advantage of the observation that mature MHC-II is short-lived on the cell surface and thus, Nef subversive action on the endocytic program responsible for the removal of MHC-II is plausible (Chaudhry et al., 2009).

Another model has been proposed for Ii upregulation. In this simpler model, Nef would increase Ii surface expression by competing for the endocytic machinery. More specifically, the dileucine motif in Nef would tritate AP-2, the adaptor protein responsible for Ii endocytosis (Mitchell et al., 2008). Although elegant, this model encounters some conflicting data, showing that a small amount of Nef is able to induce strong accumulation of Ii. Also, other receptors that depend on AP-2 for its endocytosis, such as the Transferrin receptor, are not upregulated by Nef (Schindler et al., 2003). Nevertheless, this could be another mechanism used for Ii upregulation and still cannot be discarded. 


\subsection{Cellular activation by Nef}

It is now clear that Nef is capable of mimicking transcriptional programs in order to manipulate the cell activation status in a way that favors HIV pathogenesis in a myriad of ways. The Nef protein can deliver antiapoptotic signals to the infected cells in order to sustain a prolonged infection, create a viral reservoir, or increase the number of permissive cells for viral infection (Mahlknecht et al., 2000). In a contrary fashion, it can stimulate apoptosis in bystander CD8+ T lymphocytes to evade immune response (Xu et al., 1999). In any case, the cell reprogramming induced by Nef is not only limited to manipulation of apoptosis. It also includes the activation or suppression of cell signaling pathways (Mahlknecht et al., 2000; Mangino et al., 2007; Percario et al., 2003; Varin et al., 2003).

Although the effects of Nef sometimes seem contradictory it must be stressed out that its functions are the product of many protein-protein interactions that can take place during different steps of the viral replication cycle in the infected cell and are subjected to Nef cellular trafficking and conformational status. As a myristoylated protein, Nef is addressed to cellular membranes. However, it has been shown that less than $50 \%$ of the protein locates at this site, and that the majority of Nef is cytossolic (Fackler et al., 1997; Kaminchik et al., 1994; Niederman et al., 1993; Welker et al., 1998). After membrane targeting, Nef is rapidly internalized though interaction of its C-terminal flexible loop and cell proteins involved in the endocytic pathways. It has been shown that while Nef is in its membrane-bound form it appears more compactly folded, suggesting that membrane-bound and cytossolic Nef shown distinct accessible interaction domains (Breuer et al., 2006), which could explain the distinct phenotypes of Nef. Nef's ability to dimerize or even oligomerize can also function as a mechanism of regulating Nef's effects (Breuer et al., 2006; Dennis et al., 2005).

Exogenous Nef have been shown to enter monocytes/macrophages, B cells and Dendritic Cells (DC) by adsorptive endocytosis. Nef also binds to the surface of T cells, but is not internalized by this cell type. No specific receptor to this protein has yet been identified (Alessandrini et al., 2000). The finding that Nef is found in sera of HIV+ positive subjects in a concentration of $10 \mathrm{ng} / \mathrm{ml}$ show that this protein is somehow secreted and that this event should have a role in pathogenesis. It is assumed that this concentration could be even higher in lymphnodes or other sites where virus-producing and target cells are tightly packaged (Fujii et al., 1996). Until now no mechanism by which Nef is secreted from cells have been identified. However, since it is involved in cellular trafficking and the biogenesis of the Multi-Vesicular Bodies (MVBs), it is possible that Nef is packaged in some of these vesicles that are later exocyted from the cell. Uninfected cells could internalize Nef by endocytosis, pinocytosis or other unknown mechanisms. Exogenous Nef recapitulates in part the effects described for endogenous produced Nef (Quaranta et al., 2006; Varin et al., 2003). Still, some divergences appear, as some evidences showing that Nef can have distinct effects on an infected or uninfected cell (as the stimulation of apoptotic or non apoptotic status). Thus, Nef's delivering route is also a determining factor of the phenotype modulated by Nef. Therefore, Nef fits the Trojan horse hypothesis, which suggests that the virus take advantage of the deliberate secretion of highly immunogenic virions proteins, not packaged into viral particles, capable of modulating phenotypes on nearby cells, favoring HIV infection (Gould et al., 2003).

Nef activates many cells types to, ultimately, activate CD4+ T cells (and also activates the CD4+ T cell itself). The effect of Nef on cellular activation has been described in DCs, B cells, and macrophages, all cell types known to activate CD4+ T cells (Mahlknecht et al., 2000; 
Quaranta et al., 2006; Xu et al., 2009). By activating CD4+ T cells, Nef favours infection spread, as well as increases the pool of permissive cells and transcription from the virus promoter on cells already infected.

Nef interacts with a number of serine and tyrosine protein kinases usually by its PxxP domain, known to bind proteins with SH3 domains (Saksela et al., 1995). Binding of Nef to these proteins lead to their activation, and activation of the pathway in which they are included. Some of these kinases include Hck, PAK1, Lyn, c-Raf, and p53, but many more have been described (Arold et al., 1998; Baur et al., 1997; Cheng et al., 1999; Greenway et al., 2002; Hodge et al., 1998; Lu et al., 1996; Saksela et al., 1995). Nef recruits several molecules involved in TCR signaling, as Lck and Vav (Baur et al., 1997; Djordjevic et al., 2004; Fackler et al., 1999), to glycolipid-enriched domains, leading the T-cell to a preactivation state (Simmons et al., 2001). Furthermore, Nef can activate $\mathrm{T}$ cells independently of TCR, stimulating calcium-dependent signaling by interaction with inositol triphosfate receptor on these cells (Manninen and Saksela, 2002).

Interestinglly, some effects of Nef on signaling can be seen even in the absence of the PxxP domain, as STAT3 phosphorilation. For STAT3 phosphorilation the domains necessary for interaction with the endocytic machinery, as the diacid domains EE155 and DD174 and the dileucine domain LL164 were needed, showing that interaction with SH3 domain containing proteins is not the only event related to manipulation of signaling pathways by Nef (Percario et al., 2003).

Activation of the signaling pathways by Nef leads, for instance, to the induction NFkB nuclear translocation by inducing phosphorilation of IKK alpha and beta and their subsequent degradation (Mangino et al., 2007; Varin et al., 2003). This activation leads to the secretion of pro-inflammatory mediators, as IL-1beta, IL-6 and TNFalpha, and chemokines as MIP1alpha and beta. Other pathways activated by Nef include AP-1, c-Jun, and MAPK ERK1/2, JNK and p38 (Mangino et al., 2007). This effect can take place in many cell types as promonocytic cells, Monocyte-Derived Macrophages (MDMs), and DCs (Olivetta et al., 2003; Quaranta et al., 2006; Varin et al., 2003). The soluble mediators synthesized as the result of the activation of these pathways, as IL-6 and MIP-1alpha, activate JAK, leading to dimmerization of STAT1 and 3 (Mangino et al., 2007; Percario et al., 2003). Also, as Nef activates IRF3, leading to the synthesis of IFNbeta, it also leads to STAT2 activation (Mangino et al., 2007). NFkB activation also contributes to synthesis of viral proteins, since NFkB is one of the main regulators of the viral promoter (Nabel and Baltimore, 1987).

Signaling through NFkB and STAT3 are responsible for regulation of antiapoptotic genes on infected cells, preventing their death, prolonging viral production and spread (Quaranta et al., 2006). Along with TNF, Nef stimulation of NFkB may act blocking caspase 8 activation (Wang et al., 1998).

It has been described that treatment of cells with exogenous Nef are similar to the treatment with TNFalpha, and lead to the same outcomes (Mahlknecht et al., 2000; Varin et al., 2003), as NFkB, AP-1 and JNK activation. It is thus believed that Nef might engage interactions with some actor of the TNFalpha signaling pathway, but such protein have not yet been identified (Varin et al., 2003).

Nef was found in the germinal centers of infected lymphoid follicules, and its presence has been observed in IgD+ B cells, although these cells showed no signs of infection, as they lack any other viral protein or RNA. On B cells, Nef inhibits CD40-dependent activation and IgG2 and IgA class-switch. Interestingly, Nef can reach these cells by inducing conduit 
formation on infected nearby macrophages, and trafficking through them in vesicles that are delivered to B cells (Xu et al., 2009).

AIDS is by many authors considered as the outcome of many immunological disorders. The solely expression of Nef in SCID human/mouse model recapitulates many of the AIDS symptoms (Hanna et al., 1998; Lindemann et al., 1994; Skowronski et al., 1993). Nef completely transfigures signaling of DCs, T cells, monocytes/macrophages, B cells and probably many others cell types. These attributes make this protein probably the major pathogenicity factor of HIV.

\subsection{Downmodulation of TCR/CD3}

HIV-1 infection in humans and SIVmac infection in rhesus macaques induces overall levels of immune activation associated with accelerated $\mathrm{T}$ cell turnover rates and increased susceptibility to apoptotic cell death that culminates in progression to AIDS in the absence of an effective anti-HIV therapy. Moreover, the accessory protein Nef from both HIV and SIV has been implicated in immune activation and disease progression as discussed previously. HIV-1 Nef has also been reported to directly enhance the responsiveness of T cells to activation (Fenard et al., 2005; Fortin et al., 2004; Wang et al., 2000). Nonetheless, non-human primates naturally infected with their species-specific SIVs (e.g., sooty mangabeys (SMs) and African green monkeys (AGMs)) generally do not show signs of progression to SAIDS (Silvestri et al., 2007; VandeWoude and Apetrei, 2006). The mechanism underlying the remarkable difference in the outcome of infection between these primate hosts include $\mathrm{T}$ cell activation as a strong predictor of progression to AIDS (Giorgi et al., 1999; Sousa et al., 2002).

The signaling cascade which leads to T-cell activation and differentiation depends on the immunoreceptor tyrosine activation motifs (ITAMs) of the TCR/CD3 complex localized in cell surface for initiation of signaling cascades, thereby resulting in recruitment and activation of multiple protein tyrosine kinases, signaling intermediates, and adapter molecules (Guy and Vignali, 2009). TCR/CD3 complexes are composed of the clonotypic a $\beta$ heterodimer, the CD3 $\delta \varepsilon$ and $\gamma \varepsilon$ heterodimers, the $\zeta$ homodimer and contain a total of 10 ITAMs (Alcover and Alarcon, 2000). TCR/CD3 complexes are relatively stable but are constantly internalized and recycled back to the cell surface by the endocytosis and intracellular trafficking pathway of membrane receptors. Besides the host TCR/CD3 complexes equilibrium, SIV and HIV-2 Nef bypasses the mechanisms that normally mediate the recruitment of TCR/CD3 complexes to the endocytic machinery, therefore, SIV and HIV-2 Nef target the CD3- $\zeta$ subunit and accelerate its endocytosis rate (Howe et al., 1998; Swigut et al., 2003). The proposed mechanisms for TCRCD3 endocytosis induced by SIVmac and HIV-2 Nef proteins are based on the interaction of Nef with the CD3- $\zeta$ subunit via the AP-2 clathrin adaptor pathway (Bell et al., 1998; Howe et al., 1998; Swigut et al., 2003).

Although HIV-1 Nef fails to downregulate CD3 (Foster and Garcia, 2008) essentially all SIV Nefs, except for a small subset, downmodulate TCR/CD3 complexes to suppress $\mathrm{T}$ cell activation and programmed cell death (Kirchhoff et al., 2008). The exceptions include the chimpanzee precursor of HIV-1, SIVcpz, as well as SIVgsn, SIVmus, SIVmon, SIVgor and SIVolc. In contrast, the majority of nef alleles, including those of SIVsmm, SIVmac, and HIV2 but also those of SIVrcm, SIVdeb, SIVsyk, SIVblu, SIVsun, SIVtan, SIVsab, SIVden, SIVwrc, SIVgri, SIVlho, and SIVasc downmodulated TCR/CD3 efficiently (Schindler et al., 2006; Schmokel et al., 2011). 
In a previous report, an association between Nef proteins of all $v p u$-containing viruses and the loss of ability to down-modulate the TCR/CD3 was demonstrated, hence only vpucontaining viruses were predicted to be unable to down-modulate the TCR/CD3 complexes, e.g. HIV-1, SIVcpz, SIVgor, SIVgsn, SIVmus, SIVmon (Schindler et al., 2006). Exceptions to this association has been demonstrated since in SIVden strain, in which Nef retains the ability to downmodulate TCR/CD3, the vpu gene is present, whereas in SIVolc, which does not contain Vpu, Nef protein is unable to perform this function (Schmokel et al., 2011).

Besides the role of Nef in TCR/CD3 downmodulation a question remains to be understood: does CD3 downregulation contribute to the nonpathogenic phenotype of natural SIV infections? The reports suggest that a protective role of Nef-mediated TCR/CD3 downmodulation is needed to reduce the stimulation of virally infected CD4+ helper T cells by antigen-presenting cells and might contribute to the nonpathogenic phenotype of natural SIV infections. Inefficient CD4+ helper T cell activation would weaken the antiviral immune response and might allow the virus to persist at high levels. Indeed, reduced $\mathrm{T}$ cell activation, proliferation and apoptosis might also allow the host to maintain a functional immune system (Kirchhoff et al., 2008). However, two models of experimental SIV infection appear to be contradictory to this hypothesis. First, SIVmac, a virus inadvertently transmitted from naturally infected SMs to macaques in captivity (Daniel et al., 1985), causes immunodeficiency and SAIDS in macaques despite the fact that its Nef protein efficiently downmodulates TCR/CD3. Second, SIVmac viruses harboring the HIV-1 nef gene (the socalled Nef-SHIVs) do not induce greater pathogenicity than wild-type SIVmac in experimentally infected macaques (Alexander et al., 1999). Taken together, further analyses are required to clarify the biological significance of CD3 downregulation to the pathogenicity of SIV, HIV-1, and HIV-2 for their hosts.

Although compeling evidences that the functions of Nef described above can be related to primate lentiviral pathogenesis, each one of them individually can be excluded as the mechanism by which this protein increases viral infectivity by a number of other evidences. Nef is a multifunctional protein and besides interacting with a multitude of host cellular factors and to contribute to virus pathogenesis it seems to play a key role during the primate lentiviral replication cycle to make viral particles optimally infectious. The participation of Nef during the different steps of the primate lentiviral replication cycle will be reviwed in the next sections.

\subsection{Interference with cell cytoskeleton}

It has been demonstrated that HIV-1 takes advantage of the cytoskeleton dynamics in order to ensure viral entry and transport within and egress from target cells, as well as to interfere with other cellular processes (Fackler and Krausslich, 2006). The specific interference of Nef with cell cytoskeleton for virus entry will be discussed on section 4.1.

Nef's interference on the actin dynamics is also an important mechanism for Nef-induced alterations of T-cell receptor (TCR) signaling (Haller et al., 2006; Rudolph et al., 2009). TCR engagement triggers actin rearrangements that control receptor clustering for signal initiation and dynamic organization of signaling protein complexes to form an immunological synapse. Nef inhibits immunological synapse formation by a dynamic process involving rapid actin modifications (Thoulouze et al., 2006). TCR signaling events at the immunological synapse, including F-actin remodeling and re-localization of Lck, are evolutionary conserved activities of highly divergent lentiviral Nef proteins (Rudolph et al., 
2009). Indeed, alteration of the endocytic and signaling pathways at the immunological synapse likely impacts the function and destiny of HIV-1-infected cells. T-cell chemotaxis constitutes an essential function of the immune response, since active secretion of chemokines controls homing and recruitment of leukocytes into tissues. A number of studies have reported that Nef affects T-cell chemotaxis through the modulation of RhoGTPase-regulated signaling pathways (Janardhan et al., 2004; Lee et al., 2008; Swingler et al., 1999).

HIV-1 infection of primary human macrophages induces the formation of tunneling nanotubes (TNT) by Nef (Lamers et al., 2010). TNT is a novel communication system observed in immune cells, including B, T and NK cells, neutrophils and monocytes, as well as in neurons and glial cells, which can be utilized by HIV to spread viral particles by an intercellular route (Gerdes et al., 2007).

The effect of Nef is dependent on its myristoylation and SH3 domains. While Nef myristoylation is required for its membrane association, the proline-rich SH3-binding domain is involved in Nef association with Vav, DOCK2-ELMO1, Rac and the cellular kinase Pak2 (Roeth and Collins, 2006). First, Vav is activated by the interaction between its C-terminal SH3 domain and PxxP motif in Nef leading to Vav's downstream effectors activation, resulting in morphological changes, cytoskeleton rearrangements and the activation of the c-Jun $\mathrm{N}$ terminal kinase (JNK)/stress-activated protein kinase (SAPK) cascade (Fackler et al., 1999). Then, Nef activates Rac by binding the DOCK2-ELMO1 complex, a key activator of Rac in antigen- and chemokine-initiated signaling pathways, and this interaction is linked to the abilities of Nef to inhibit chemotaxis and promote T cell activation (Janardhan et al., 2004). Finally, Nef association with Pak2 prevents actin remodeling to impair host cell motility by disregulation of cofilin, which is an actin-depolymerizing factor that promotes actin turnover and subsequent cell motility (Stolp et al., 2010).

The cytoskeleton reorganization induced by Nef is associated with an impairment of cell movements combined with induction of long filopodium-like structures in T lymphocytes (Stolp et al., 2010). In summary, Nef displays a variety of complex effects on the motility and cellular morphology of HIV-1-infectected T lymphocyte, thus resulting in a strategy to improve immune evasion and viral spread in the infected host.

\section{SIV Nef to counteract a cellular restriction factor?}

\subsection{Tetherin and Nef}

The cellular protein Tetherin (also known as BST-2, CD317, or HM1.24) is a membrane protein with a number of distinct characteristics indicating that it plays a straight role in suppressing the release of virions from infected cells. Tetherin was discovered in 2008 when groups of Bieniasz and Guatelli were investigating the HIV-1 Vpu anti-Tetherin activity during the virus life cycle (Neil et al., 2008; Van Damme et al., 2008). The N-terminal of this protein is localized in the cytoplasm, followed by a transmembrane domain and a coiled-coil extracellular domain. The extracellular domain contains two N-linked glycosylation sites that are modified by a glycosyl phosphatidyl inositol (GPI) membrane anchor at the Cterminus (Kupzig et al., 2003; Rollason et al., 2007).

Tetherin functions as a broadly acting antiviral factor because besides lentiviruses, Tetherin restricts the release of different retroviruses, including alpha-, beta-, delta-, spumaviruses, and other viruses as arena- (Lassa), filo- (Marbuburg, Ebola), and herpesviruses (KSHV) (Mansouri et al., 2009). Tetherin belongs to the three main classes of restriction factors in addition to 
APOBEC3G, which induces hypermutation in the retroviral genome, and the Tripartide Motif Protein 5a (TRIM 5a), which acts as new incoming retroviral capsid restriction factor (Neil et al., 2008). HIV-1 overcomes these restrictions factors by the action of accessory proteins as Vif and Vpu that act against cellular substrates APOBEC3G and Tetherin, respectively, to ensure viral persistence, replication, dissemination, and transmission (Malim and Emerman, 2008).

Tetherin is antagonized by the HIV-1 protein Vpu (Neil et al., 2008; Van Damme et al., 2008). $\mathrm{Vpu}$ interact directly with the transmembrane domain of Tetherin with a high specificity (Gupta et al., 2009; McNatt et al., 2009). The mechanism by which Vpu remove Tetherin from the cell surface was proposed as Vpu recruits $\beta-\operatorname{TrCP}$, a substrate adaptor for an SCF E3 ubiquitin ligase complex, to remove Tetherin via post-endocytic membrane trafficking events (Douglas et al., 2009; Mitchell et al., 2009). As a consequence, Vpu leads to moderately reduced levels of Tetherin at the host cell surface and a modest decrease in total cellular Tetherin (Douglas et al., 2009; Mitchell et al., 2009; Van Damme et al., 2008).

Anti-Tetherin factors are also found in other viruses. Kaposi's sarcoma-associated herpesvirus (KSHV) uses K5/MIR2 protein to ubiquitinate and target Tetherin for degradation (Mansouri et al., 2009). Ebola virus glycoprotein antagonizes Tetherin-mediated restriction (Kaletsky et al., 2009; Lopez et al., 2010). Vpu functions as an anti-Tetherin factor in lentiviruses as SIV from Skye's monkeys (Lopez et al., 2010). Since lentiviruses of the SIVsmm/mac/HIV-2 lineage do not have a $v p u$ gene to impair Tetherin aactivity, this role was taken by other viral proteins. Some primate lentiviruses (e.g., SIVsmm, SIVmac, and SIVagm) use the Nef protein to antagonize Tetherin (Jia et al., 2009). SIVcpz from chimpanzees and SIVgor from gorillas, which contain the vpu gene and are the ancestors of HIV-1, also use Nef to antagonize Tetherin (Yang et al., 2010). HIV-2 on the other hand, uses its envelope glycoprotein Env (and not Nef) to downmodulate Tetherin (Bour et al., 1996; Le Tortorec and Neil, 2009; Ritter et al., 1996). SIVtan from Tantalus monkeys uses both Env and Nef to antagonize Tetherin (Gupta et al., 2009; Zhang et al., 2009).

Analyses of the interactions between Tetherins from different primate species and the antagonist proteins used by viruses that infect those hosts have revealed a high degree of species-specificity. For example, the HIV-1 Vpu protein antagonizes human but not monkey Tetherin (Gupta et al., 2009; McNatt et al., 2009). These antiviral factors have sequence divergences that may constitute barriers to zoonotic viral transmission from animal reservoirs. For instance, the specificity of SIV Nef for rhesus Tetherin mapped to a four amino acid sequence in the cytoplasmatic domain that is missing from the human protein, whereas the specificity of HIV-1 Vpu for human Tetherin mapped to amino acid differences in the transmembrane domain (Jia et al., 2009).

Tetherin is usually only expressed efficiently in plasmacytoid dendritic cells, some cancer cells, terminally differentiated B cells, and bone marrow stromal cells (Blasius et al., 2006; Goto et al., 1994; Ishikawa et al., 1995) and its expression is strongly induced by type I Interferons (Neil et al., 2007). Tetherin is constitutively expressed on the surface of HeLa, Hep-2 and Jurkat cells lines but is not detected in other cell lines, such as 293T, HOS and Cos-7 cells (Van Damme et al., 2008). The absence of Tetherin expression in some cell lines suggest that the anti-Tetherin function of $\mathrm{Vpu}$ or Nef may not be obligatory for efficient viral replication in vitro and disease progression in vivo. It also remains to be determined whether Tetherin will promote or block cell-to-cell transmission (Gummuluru et al., 2000; Neil et al., 2006; Neil et al., 2008; Vendrame et al., 2009). Thus, further studies on the effect of Tetherin for primate lentiviral replication are necessary. 


\section{Nef and the basic steps of the HIV and SIV replication cycle}

\subsection{Nef and virus entry and uncoating}

HIV and SIV enter target cells by fusion of the viral envelope with the cell membrane followed by the delivery of the virion core inside the cell cytoplasm. The host cell cytoskeleton imposes the first physical barrier to viral invasion upon entry and Retroviruses have evolved mechanisms to interfere with cytoskeleton arrangement. More specifically, it has been proposed that Nef could reorganize actin to ensure initial viral core movement. Association of Nef with viral cores (Kotov et al., 1999) and cellular proteins involved in actin cytoskeleton dynamics such as Vav and PAK (a member of the p21-activated kinase family) could account to the early movement of the viral cores through cortical actin and into microtubules (Roeth and Collins, 2006). Therefore, it has been proposed that this function of Nef could account to the increase in virus infectivity (Campbell et al., 2004).

Lentiviruses infect non-dividing cells implying that the recently formed viral DNA enters the nucleus through the nuclear pore. In fact, the so-called Pre-Integration Complex (PIC), formed by the double strand viral DNA associated with the viral Integrase (IN) and other viral and cellular proteins gains access to the nucleus by being actively transported through the nuclear pore. This phenomena imposes the necessity of an uncoating step because the diameter of the viral core $(60 \mathrm{~nm}$ wide) exceeds that of the nuclear pore $(30 \mathrm{~nm})$ (Arhel, 2010). Uncoating is the process of core disassembly that takes place after virus entry into the host cell. Three distinct models of lentivirus uncoating have been proposed: i) in the first model it is predicted that disassembly occurs spontaneously and immediately after the viral core has entered the cell cytoplasm; ii) in the second model disassembly occurs in a time frame when the reverse transcription of the viral RNA has already started; iii) in the third model core disassembly occurs later on when the synthesis of the viral DNA is already completed and the Reverse Transcription Complex (RTC) is in close proximity of the nuclear membrane. Recent evidences favor the third model.

Disassembly of the viral cores has to occur in an optimal rate to ensure that reverse transcription is successfully completed. This was evident from studies demonstrating that mutations in Gag affecting core stability reduced reverse transcription in cells (Brun et al., 2008; Forshey et al., 2002). Since Nef-deleted viruses have a defect in reverse transcription unrelated to a direct role of Nef in the Reverse Transcriptase (RT) activity (which will be discussed in section 4.2), it was proposed that the absence of Nef in the incoming viruses would affect core stability, compromising uncoating and therefore reverse transcription. However, studies failed to show this effect of Nef ruling out a role for Nef during viral uncoating (Cavrois et al., 2004; Forshey and Aiken, 2003).

Interestingly, the route of viral entry seems to dictate the Nef requirement for optimal infectivity. Whereas wild type HIV-1 or amphotropic murine leukemia glycoproteinpseudotyped HIV-1 virions that promote membrane fusion and cell entry through the plasma membrane are dependent on Nef to be fully infectious, HIV-1 virions pseudotyped with the glycoproteins for which fusion and entry take place after endocytosis and upon endosome acidification (e.g. Vesicular Stomatitis Virus glycoprotein - VSV-G) do not require Nef to increase infectivity (Aiken, 1997; Chazal et al., 2001; Luo et al., 1998). As pointed out previously, the treatment of target cells with drugs that disrupt the cortical actin cytoskeleton complements the infectivity defect of Nef-deleted virus (Campbell et al., 2004). Therefore, taken together, and discarding the role of Nef in facilitating viral uncoating (Cavrois et al., 2004; Forshey and Aiken, 2003), these findings have been interpreted as 
evidence for a role of Nef in facilitating the penetration of the viral cores through the cortical acting barrier, a function that would become dispensable if entry occurs through endocytosis. However, it was recently demonstrated that the presence of Nef itself in viral particles by means of its incorporation through Vpr (Nef.Vpr fusion protein) was not sufficient to increase viral infectivity (Laguette et al., 2009). Moreover, it has been shown that in some cases the requirement for Nef to achieve optimal viral infectivity is not circumvent by directing viral entry through endocytocis followed by exposure to low $\mathrm{pH}$. In an elegant study it was shown that pseudotyping HIV-1 cores with the Rous Sarcoma Virus A (RSV-A) receptor, the Tva molecule, and using this pseudotypes to infect cells harboring the RSV-A glycoprotein Nef was still necessary for optimal infectivity (Pizzato et al., 2008). Therefore it remains to be fully established that the importance of Nef to the increase of viral infectivity is solely related to its effect on the actin rearrangement upon viral entry and whether other components of the viral core also contribute in the process.

\subsection{Nef and reverse transcription}

Upon entry to the target cell the reverse transcription step of the Retroviral replication cycle is initiated. Reverse transcription is defined as the synthesis of the viral double strand DNA (dsDNA) from the viral single strand RNA genome (ssRNA), which is catalyzed by the two sub unities of the viral Reverse Transcriptase (RT), p66 (polymerase and RNase H) and p51 (polymerase). A pre-requisite to reverse transcription is the formation of a pre-initiation RTC during viral maturation within the producer cell. Minimally, the pre-initiation RTC is composed by two copies of the viral ssRNA genome, the tRNA primer and the viral enzymes RT and IN. Other viral proteins including nucleocapsid (NC) and the accessory proteins Vpr and Nef are also part of the pre-initiation RTC (Warrilow et al., 2009). An important characteristic of the pre-initiation RTC for most of the retroviruses is that, in virions, it undergoes minimal reverse transcription and this event is trigged in the target cell by factors that are still not completely understood. One of the major events triggering reverse transcription seems to be the exposure of the RTC to the non-limiting concentration of deoxyribonucleotides within the target cells. Once the reverse transcription is initiated structural changes occur releasing most of the protein content of the pre-initiation RTC, turning it into a mature RTC. For instance, most of the RT and the Nef content is shed at this time. It is being now recognized that cellular proteins such as helicases and other cellular factors are also present at the RTC and must play important roles during reverse transcription (Warrilow et al., 2010). The RTC migrates towards the nuclear pore through association with the cell cytoskeleton and once reverse transcription is completed the RTC is fully maturated in the PIC to enter the nucleus for the next step of viral dsDNA integration (Warrilow et al., 2009). One of the models of uncoating discussed previously predicts that only at the stage of fully maturation of the RTC into PIC is that most of the CA protein content is shed. Therefore, uncoating occurs later after reverse transcription and implies that an optimal core microenvironment is maintained in order to avoid dilution of the crucial RTC contents and the attack of deleterious cellular factors (Arhel, 2010).

Reverse transcription occur in two distinct phases; the early phase encompasses the formation of the negative strand DNA (cDNA) from the genomic RNA, while in the late phase the positive strand DNA is synthesized from the cDNA generating the dsDNA. RT is the sole enzyme that catalyses the DNA synthesis and the degradation of the viral RNA template. However, IN has a crucial role during the initiation of the reverse transcription by 
physically interacting and increasing the processivity of the RT (Dobard et al., 2007; Wu et al., 1999). Therefore, not only the high stoichiometry of the RT must be maintained during reverse transcription but also that of the IN. Other viral proteins have been implicated in facilitating or participating in reverse transcription. For instance, NC and Vpr physically interact with RT as well as with IN and may play an important role during the initiation of reverse transcription (Warrilow et al., 2009).

The presence of Nef in the RTC is well documented (Forshey and Aiken, 2003; Kotov et al., 1999), as well as its function in stimulating the synthesis of the viral dsDNA during reverse transcription in the target cell (Aiken and Trono, 1995; Schwartz et al., 1995). However, Nef does not influence RT activity per se since the in vitro activity of RT from Nef-deleted viruses is not altered and the treatment of these viruses with deoxyribonucleotides previous to infection of the target cells restores viral infectivity (Aiken and Trono, 1995; Khan et al., 2001). These observations prompt to the conclusion that Nef would function in an early step during the viral replication cycle before reverse transcription. Studies have failed to demonstrate any influence of Nef in virus entry, delivery of the viral cores to the cell cytoplasm or core disassembly (Cavrois et al., 2004; Forshey and Aiken, 2003; Miller et al., 1995). Other study had shown however that this early effect of Nef can be attributed to a post-entry event like facilitating the movement of the viral core through cortical actin located beneath the plasma membrane (Campbell et al., 2004), however this has recently being disputed since two different studies demonstrated that the effect of Nef in increasing viral infectivity derives not from its presence in the viral particles but from some effect on the virus producer cell (Laguette et al., 2009; Pizzato et al., 2008).

\subsection{Nef and virus assembly}

The viral genomic RNA is transported to the cytoplasm were it leads to the synthesis of the Gag and GagPol polyprotein precursors. These precursors oligomerize and traffic to the plasma membrane by still not completely understood pathway(s). Concomitantly, the Env glycoproteins are translated in the ER and are transported to the plasma membrane via the secretory pathway. Membrane-targeted Gag and GagPol polyproteins recruit the viral genomic RNAs and assemble at the plasma membrane, leading to the induction of membrane curvature at the site of assembly, while the Env glycoproteins are incorporated into the budding particles during the assembly process. Experimental evidences suggest an important role for lipids and especialized cell membrane microdomains for the optimal assembly of HIV-1.

Also, HIV and SIV and many other viruses infect their target cells by interacting with the surface membrane microdomains enriched with cholesterol, sphingolipids and other saturated lipids, as well as specific types of proteins, referred as lipid rafts or detergentresistance membranes (DRMs) (Nayak and Hui, 2004). Lipid rafts form a liquid-ordered state through lipid-lipid interactions and are central for attachment of proteins when membranes are moved around inside the cell and during signaling transduction (Verkade and Simons, 1997). Glycosylphosphatidylinositol (GPI)-anchored proteins, transmembrane proteins and doubly acylated tyrosine kinases of the Src family all associate and are incorporated into DRMs.

Moreover, Nef has been proposed to have a role during the assembly step of the viral replication cycle. Several studies reported that HIV-1 Nef expression alters the lipid composition of virions by increasing cholesterol biosynthesis and its incorporation into 
DRMs, therefore Nef increases the concentration of Gag and colocalizes with viral structural components in the DRMs. These features were linked to the increase in viral infectivity and the facilitation of virus spread (Wang JK, 2000; Zheng et al., 2003). Also, it seems that infectivity enhancement by Nef requires its association with components of the assembling HIV/SIV particles. Gag from HIV/SIV associates with DRMs and disruption of Gag-raft interactions impairs virus particle production (Chukkapalli et al., 2010). It has been demonstrated that fusion of the host protein cyclophilin A (СуpA) to Nef allowed controlled incorporation of Nef into HIV-1 particles via association with Gag during viral particle assembly for enhancement of HIV-1 infectivity (Qi and Aiken, 2008).

Besides the effect of Nef association with DRMs to viral infectivity, Nef also associates with these membrane microdomains together with several proteins involved in the initiation and propagation of $\mathrm{T}$ cell signaling and could therefore affect the later steps of the replication cycle. Nef was shown to interact with Pak-2 in lipid rafts (Krautkramer et al., 2004), which may result in increased frequency of cells expressing transcriptionally active forms of NF-KB and NFAT and increased T cell activation (Fenard et al., 2005). The interaction of Nef with PAK2 is conserved for many Nef proteins derived from HIV-1, HIV-2, and SIV strains (Sawai et al., 1995), and was demonstrated to be mediated by Cdc42 and Rac, which are PAK 2 activators, and being dependent on raft integrity (Krautkramer et al., 2004). While delivers activation stimulus to CD4 T cells Nef also mediates exclusion of molecules such as Lck, Vav, and TCR $\zeta 2$ known as ubiquitin-conjugating enzyme (UbcH7) from rafts in lipid rafts to avoid the negative regulation of $\mathrm{T}$ cell signaling (Simmons et al., 2005).

Rafts were also initially proposed to act as platforms for virus entry, facilitating interactions between CD4 receptors and the incoming virions (Chukkapalli et al., 2010). This role has been, however, questioned, because CD4 molecules unable to associate with rafts still allow virus entry (Percherancier et al., 2003; Popik and Alce, 2004). Moreover, Sol-Foulon and coworkers proposed that the effects of Nef on CD4 downregulation and the increase in viral infectivity were independent of lipid rafts (Sol-Foulon et al., 2004). Discrepancies in methodological approaches from these authors with the reports described before could account for the observed differences on this effect of Nef. Therefore, more detailed studies are needed in order to establish a connection between the localization and the effects of Nef in DRMs and its importance for virus replication and infectivity.

Endocytosis may be classified into two categories, clathrin dependent and independent. The role of Nef in inducing clathrin-dependent endocytosis of some surface receptors, as CD4 (Aiken et al., 1994; Chaudhuri et al., 2007; Garcia and Miller, 1991; Mariani and Skowronski, 1993), triggering the de novo formation of clathrin coated pits and acting as a connector between receptor cargo and the endocytic machinery (Foti et al., 1997) has been addressed here. Dyn2 was identified as a Nef binding partner through immunopreciptation assays, and is intrinsically related to clathrin-dependent endocytosis (Pizzato et al., 2007). It is a ubiquitously expressed member of large GTPases that is thought to aid the fission step that separates clathrin-coated vesicles from the plasma membrane (Hinshaw, 2000). Nef distinguishes between the three isoforms of Dyn, binding specifically to Dyn2, and this interaction is conserved among different nef alleles. The interaction is dependent of the Middle and GTPase Effector domains of Dyn2 and surface-exposed core domain residues in Nef, as L112, F121 and D123. Loss of Dyn2 interaction leads to loss of infectivity, however, Nef mutants that are able to bind Dyn2, as LL164,165AA, also show infectivity impairment, showing that Dyn2 interaction is not sufficient for Nef induced infectivity enhancement 
(Pizzato et al., 2007). Interestingly, this was the same domain considered crucial for sorting of Nef on clathrin coated vesicles, showing that Nef may have multiple mechanisms in order to gain access to clathrin-dependent endocytosis (Greenberg et al., 1998a).

Furthermore, the increase in viral infectivity by Nef through binding to Dyn2 is dependent on clathrin and the proposed mechanism predicts that by binding to Dyn2 Nef would gain access and selectively modify specific membrane domains in the infected cell from which viral assembly occurs (Pizzato et al., 2007). On the other hand, clathrin by its turn may also have another direct role during HIV infection. At least for HIV-2 and SIVmac, the p6 peptide within Gag is thought to directly engage clathrin, by a motif that resembles the classic clathrin box, LLpL(-), where $\mathrm{p}$ is a polar residue and (-) a negatively charged one (Kirchhausen, 2000; Popov et al., 2011). It was also shown that although HIV-1 lacks such sequence in Gag or GagPol, it may also engage clathrin through GagPol, in a mechanism dependent of the IN region of this polyprotein (Popov et al., 2011). This might be explained by the enhanced GagPol dimerization rate that a GagPol precursor deleted in the IN domain possess, which could occlude a putative clathrin interaction surface (Bukovsky and Gottlinger, 1996). Since Nef interacts with GagPol and PR, it may also decrease GagPol dimerization, resulting in a better-exposed clathrin interacting surface (Costa et al., 2004; Miller et al., 1997; Pandori et al., 1998).

\subsection{Nef and virus budding}

The endo-lysosomal sorting machinery was first described in yeasts, but is well conserved in mammals. In yeasts it is called VPS pathway (for Vacuolar protein sorting), and the proteins of this pathway are denominated class E proteins, as their inactivation leads to the formation of an enlarged and abnormal membrane compartment. Class E proteins can present themselves as isolated proteins or as hetero-oligomeric complexes of high molecular weight known as ESCRT (Endosomal Sorting Complex Requires for Transport) (von Schwedler et al., 2003).

In mammals, this machinery is involved in the sorting of proteins to many cellular compartments, as endosomes, lysosomes, Golgi complex and endoplasmatic reticullum. The pathway initiates with the ESCRT-I recruitment to the already ubiquitinated (ESCRT tagging) cytoplasmatic portion of the protein to be sorted. This first recruitment is made by the cellular proteins STAM and HRS (referred by some authors as ESCRT-0). From this point, two pathways might be taken: ESCRT-I activates a second complex named ESCRT-II, or it recruits Alix/AIP-1, a central protein of the ESCRT pathway, but that is not a stable part of any of the three complexes. In both cases, the ESCRT-III is recruited, whose factors bind directly to intracellular membranes and promote its invagination, usually to an endosome. Due to its morphology, endosomal compartments that contain vesicles in its interior are called Multivesicular Bodies (MVBs). This structure might have two fates, lysosomes fusion, delivering its content to degradation, or fusion with the plasmatic membrane, liberating its vesicles as exosomes (Strack et al., 2003).

The topology of viral budding is analogous to the MVBs formation, and to the membrane fission event that happens on mitosis. Therefore it is reasonable that the same cytoplasmatic machinery used for the MVBs biogenesis is co-opted by viral specific motifs in viral proteins named late domains in order to perform viral budding (Fujii et al., 2007).

Three types of late domains have been characterized in a variety of viral proteins: $P(T / S) A P$, responsible for the interaction with the ESCRT-I component, Tsg101; PPxY, that engage 
interactions with the Nedd4 ubiquitin ligase family; and YPxL, that interact with Alix/AIP-1 (Freed and Mouland, 2006). The fact that these late domains maintain its functionality even when translocated to other regions of viral proteins or swapped between distinct viruses suggest that they serve as anchoring sites to cellular factors, rather than structural elements (Garrus et al., 2001).

On HIV-1 and SIV, the budding process initiates concomitantly with the end of the viral particle assembly, which is orchestrated by the different Gag domains. The PTAP motif contained in p6 peptide within Gag is considered the main late domain of HIV. However, the HIV genome holds two more late domains, the YPxL also located in p6 and the YPLT domain in Nef, both capable of interacting with Alix/AIP-1. Nef physical and direct interaction with Alix/AIP-1 has been demonstrated both in vivo and in vitro (Costa et al., 2006). Nef can substitute for the L domain of a p6-deleted Gag polyprotein when fused to its C-terminal, restoring viral budding. Also, a Vpr.Nef chimera was able to restore viral budding when the PTAP domain in p6 was disrupted (Costa et al., 2006).

In CEM and SupT1 cell lines, Nef was shown to increase biogenesis of MVBs, a feature that can be useful for budding (Costa et al., 2006; Stumptner-Cuvelette et al., 2001). HIV budding toward MVB was seen in many cell lines, and can be especially decisive in macrophages, a lineage known to have well-developed endosomal machinery. Accumulation of late endosomes was dependent of the YPLT domain in Nef, and requires Nef interaction with Alix/AIP-1.

\subsection{Nef and virus maturation}

The retrovirus enzymatic and structural proteins are produced by the translation of a polycistronic RNA and originate the polyprotein precursors Gag and GagPol (Frankel and Young, 1998). The viral PR (Navia et al., 1989) catalyses the hydrolysis of the peptide bonds of the polyproteins' cleavage sites originating the mature proteins capable of generating an infectious particle (Louis et al., 2000).

The lentiviral PR is composed of 99 amino acids, and is synthesized as part of the GagPol precursor polyprotein. As it contains an aspartic acid in the center of the catalytic domain, the HIV and SIV PR are classified as members of the aspartyl PR family (Navia et al., 1989). Some features separate cellular aspartyl PRs from primate lentiviral PR. Unlike cellular aspartyl PRs, which are monomeric, viral aspartyl PRs are dimeric and must dimerize in order to gain catalytic activity. Therefore, the first step of PR activation is the dimerization of two GagPol molecules (Pettit et al., 2005; Weber, 1990). Other feature is that the cleavage sites recognized by HIV and SIV PR do not share amino acid identity on the cleavage sequence, or on its flanking regions (Hellen et al., 1989; Krausslich et al., 1988). Finally, the last characteristic that separate HIV and SIV PR from its cellular relatives is that, as for cellular PRs the whole catalytic machinery is pre-formed, and its activation lies mostly on the cleavage of a zymogen (Tang and Wong, 1987), for HIV and SIV PR the activation is extremely controlled by mechanisms involving protein folding, zymogen cleavage, PR context, interactions and pH (Gatlin et al., 1998; Partin et al., 1991; Pettit et al., 2004). These abundant regulatory mechanisms point out that the correct PR activation is essential for the formation of infectious particles, and that a premature activation must be avoided. Such activation could lead to complete viral processing before the completion of budding, resulting in the diffusion of viral constituents on the cytosol and altering the protein ratio in the budding particle (Pettit et al., 2004). 
After dimerization, the first cleavages events occur in cis. The first cleavage site is located between sp1 and $\mathrm{NC}$, and the second is inside the $6^{*}$ region of the GagPol precursor polyprotein, divinding $\mathrm{p}^{*}$ in an octapeptide (sometimes referred as Transframe Peptide, TFP) and a 48 amino acids region that is immediately upstream the PR. These two cleavages generate the processing intermediates MA-CA-sp1 (42KDa), NC-TFP (7,4KDa) from Gag and p6*-PR-RT-IN (113KDa) from Pol (Pettit et al., 2004). It is thought that at this point p6* acts as a zymogen, lying on the catalityc center and blocking further cleavages (Partin et al., 1991). In order to continue processing an event capable of dislodging $\mathrm{p}^{*}$ from the catalic site is needed. Many events have been alleged as capable of so. The $\mathrm{pH}$ decay that occurs during the budding is the fit theory. However, it is not excluded that some cellular or viral protein may participate in this process. For instance, it has been demonstrated that the viral accessory protein Nef binds specifically to the $6^{*}$ region of the GagPol precursor (Costa et al., 2004; Jesus da Costa et al., 2009).

It is well established that the Nef protein from both HIV-1 (Chen et al., 1998; Freund et al., 1994; Miller et al., 1997; Pandori et al., 1998) and -2 (Schorr et al., 1996) is cleaved by the viral PR. Initially, the cleavage site within Nef was demonstrated to localize to the Nterminal region generating a $9 \mathrm{kDa}$ membrane anchor domain and a $20 \mathrm{kDa}$ Nef core domain (30kDa core domain in the case of HIV-2). These cleavage forms of Nef are recognized only inside the viral particles, implying that cleavage takes place during the viral maturation step that culminates with the formation of mature infectious viruses. Although the HIV-2 PR cleaves Nef from HIV-1 (Schorr et al., 1996), there is no amino acid sequence conservation of the cleavage sites between Nef from HIV-1 and HIV-2. While in the HIV-1 Nef the well established cleavage site localizes between the Tryptophan 57 and Leucine 58, in the amino acid sequence context 54DCAW*LEAQ61, in HIV-2 Nef the cleavage site is localized between the Tyrosine 39 and Serine 40 in the amino acid sequence context 36GGEY*SQFQ43. Another cleavage site within HIV-1 Nef must exist since two independent groups reported a C-terminal cleavage form of Nef with an apparent molecular weight of $13 \mathrm{kDa}$ (Laguette et al., 2009; Miller et al., 1997). Recent data from our group demonstrated that the SIVcpz PR also cleaves Nef from SIVcpz during the virus replication cycle probably at the same residues as in HIV-1 Nef. Moreover, we have also observed that the SIVcpz PR has the capacity of cleaving Nef from HIV-1 generating a Nef core domain with the same apparent molecular weight when cleaved by the HIV-1 PR (Sampaio, manuscript in preparation). Since there is a great degree of conservation between the nef genes from HIV-2 and SIVmac it is likely that the Nef protein from SIVmac is also cleaved by the viral PR.

The fact that Nef is cleaved by the viral PR implicates that these proteins interact during the viral replication cycle, however the consequences of this cleavage for viral infectivity is still a matter of controversy. Mutations introduced at the main cleavage site on Nef, which prevent PR cleavage, does not necessarily correlates with a loss of infectivity. For instance, in one study the deletion of the cleavage site of Nef ( $\triangle$ DCAWL 54-58) prevented its cleavage and reduced viral infectivity by $80 \%$ (Miller et al., 1997), while in another study a similar deletion, which again prevented Nef cleavage, reduced viral infectivity by only 20\% (Pandori et al., 1998) (Table 1). On the other hand, mutations at the same cleavage site that did not disrupt cleavage, like W57A, had a great impact on viral infectivity (Chen et al., 1998; Miller et al., 1997). A summary of mutations and deletions introduced at the cleavage site of Nef and its impact on viral infectivity are listed on Table 
1. From this data we can observe that most of the mutations that prevented cleavage correlated with a reduction in viral infectivity, however some mutations that still allow cleavage to happen also had an impact on viral infectivity. Based on these observations authors excluded that processing of Nef by the viral PR could be related to the capacity of the former to increase viral infectivity.

Nevertheless, one can draw some conclusions from these data. First, some of the mutations considered not disrupting cleavage of Nef did in fact altered the normal rate of cleavage, as for mutations W57A and WL57AA there was much less cleavage observed (Chen et al., 1998; Miller et al., 1997), while for mutation CAW55LLL it could be observed a higher cleavage rate of the Nef protein (Miller et al., 1997). Therefore, alteration of the cleavage rate could interfere with the properties of Nef to increase viral infectivity without disrupting cleavage entirely. Second, a complicating issue is that the cleavage site of Nef is also involved with downmodulation of CD4 therefore, disruption of this domain could have consequences for viral infectivity that could be related to this well established function of Nef. But it must be pointed out that the viral infectivity data described here was obtained from CD4 negative cells ruling out the effect that these mutations would have on CD4 downmodulation. Lastly, as pointed out previously 55CAWL58 is the main viral PR cleavage site but other sites exist within Nef (Laguette et al., 2009; Miller et al., 1997). This could explain that however impairing the cleavage at the major site viral infectivity increase by Nef would not be greatly affected.

It is not the presence of Nef in the viral particles per se that increases viral infectivity. This was proven by a study by Laguette and co-workers (Laguette et al., 2009) where it was demonstrated that increasing the amounts of Nef being incorporated within HIV-1 particles by means of a Nef-Vpr fusion protein was not sufficient to make viral particles more infectious. In any case, this Nef-Vpr fusion was normally processed by the viral PR and retained classical Nef functions such as downmodulation of CD4 from the surface of virus producer cells. This data therefore indicates that the role of Nef related to the increase in viral infectivity occurs during the late stages of the replication cycle in the virus producer cells, probably by optimally regulating/modifying the structural and/or enzymatic viral components. Some aspects related to this possible function of Nef will be discussed further. Interestingly, besides connecting viral PR since being recognized as a specific substrate, Nef can also connect the structural/enzymatic polyprotein precursor GagPol through different domains either in Nef and in GagPol (Costa et al., 2004; Jesus da Costa et al., 2009). These studies demonstrated that the Nef protein from both HIV-1 (Costa et al., 2004) and SIVmac (Jesus da Costa et al., 2009) can interact with the GagPol precursor through the flexible-loop domain in Nef and the $\mathrm{p} 6^{*}$ regulatory region of GagPol. Although the specific amino acid residues involved in this interaction in both Nef and $\mathrm{p}^{*}$ were not yet demonstrated, its specificity and the biological relevance were. Interaction of GagPol and Nef occurs in cells during the HIV-1 replication cycle and was sufficient to explain the dominant negative phenotype of an laboratory adapted allele of HIV-1 nef (Nef F12) which localizes to the ER and inhibits the release of Gag and its processing by the viral PR (Fackler et al., 2001; Olivetta et al., 2000). The F12 phenotype was recapitulated by a Nef with an ER retention signal, meaning that by interacting with GagPol Nef retained this polyprotein precursor inside the producer cell avoiding both release and maturation of viral particles (Costa et al., 2004). Furthermore, the relevance of this interaction was confirmed by an experiment demonstrating that release of a late-domain defective HIV-1 from producer cells was 
rescued by a Nef-Tsg101 fusion protein, indicating that, besides interacting early during the expression of GagPol, Nef and the viral structural/enzymatic precursors are present concomitantly at the sites of virus budding. While investigating what influence the binding of Nef and GagPol would have for HIV-1 infectivity we have also established that Nef from HIV binds the cellular Alix protein and correlated these findings with optimal viral replication in cells (Costa et al., 2006). We demonstrated that this interaction correlated with the property of Nef to stimulate the synthesis of MVBs in cells and the optimal infection of MDMs. Taken together, the fact that Nef binds both the viral precursor GagPol and to the cellular Alix protein, which is involved in virus budding, suggest that Nef actively participates in a late step of viral replication. We further extended these observations to SIVmac, demonstrating that the binding of Nef to both GagPol and Alix is conserved in Nef from this virus (Jesus da Costa et al., 2009). The functional relevance of these bindings was clearly demonstrated in rhesus macaques. First, informative mutations were introduced into the nef gene of infectious SIVmac and this mutant virus used to infect four rhesus macaques. Whereas rhesus macaques infected with the WT virus developed high viral loads and progressed rapidly to SAIDS, only two of four monkeys inoculated with the mutant virus displayed a similar picture, albeit with much delayed kinetics. Importantly, in both cases, we observed reversions in SIVNef that restored its binding to SIVGagPol and Alix. In two other rhesus macaques, mutant Nef sequences persisted and they developed neither high viral loads nor SAIDS. Further studies in cells provided additional support for these findings. Taken together these studies suggest that interactions between Nef, GagPol and Alix are important for optimal viral replication and progression to disease in the monkey model of AIDS and possibly also pertinent to the human disease since these interactions are preserved in both HIV-1 and SIVmac.

Still, what would be the mechanism by which interacting with GagPol and Alix, Nef would stimulate viral infectivity? Recent work from our group demonstrated that Nef that from SIVcpz also binds to GagPol from both SIVcpz and HIV-1. Furthermore, our results showed that Nef exerts a direct influence upon the viral PR activity: i) first by characterizing a SIVcpz provirus that expresses a N-terminal truncated peptide of Nef that is a potent inhibitor of viral processing and consequently viral infectivity and exerts a dominant negative activity both against PR from SIVcpz and HIV-1 (Sampaio et al. manuscript in preparation); second by demonstrating that in the absence of Nef expression during the replication cycle of HIV-1 the processing kinetics of the Gag and GagPol precursors are accelerated, resulting in slightly lower concentration of the structural (p24-Capsid protein) and 2-fold lower concentration of the enzymatic (IN) components within viral particles (Mendonça et al. - manuscript in preparation). Moreover, the accelerated activity of the viral PR in the absence of Nef expression in the producer cells was also demonstrated by the fact that higher concentrations of PR inhibitors (e.g. Lopinavir) are required to inhibit virus replication at the same levels as of the wild type viruses. Based on this preliminary results a working model was drawn (Figure 2), in which the role of Nef for virus infectivity is explained by the following: upon binding of the $\mathrm{p}^{*}$ and PR regions, within the GagPol precursor, Nef would function as a fine regulator of PR activation, holding it to an optimal timing when budding of the viral particles is almost complete.

Therefore, the right content of the viral constituents is achieved. In the absence of Nef, PR activation would occur earlier on before the completion of budding, consequently some of 
the protein content is lost during the formation of the viral particles, especially the IN, since it is one of the first enzymes to be processed out from the GagPol precursor. How would this explain the decreased infectivity of the Nef-deficient viruses? Since IN is important not only for the integration step of the viral DNA to the host genome but also participates during the Reverse Transcription of the viral RNA, lower concentrations of the IN would affect reverse transcription of the incoming virus impacting on viral infectivity. Our results conciliates previous data demonstrating an impairment in the HIV-1 ability to reverse transcribe the viral RNA genome in Nef-deficient viruses, which could not be explained by a role of Nef in facilitating an early step of the replication cycle as enhancement of viral capsid delivery to the cytosol of the target cell (Cavrois et al., 2004; Miller et al., 1995; Tobiume et al., 2001), trafficking of the viral cores through the cortical actin network since (Campbell EM, 2004; Pizzato et al., 2008), or capsid uncoating (Cavrois et al., 2004; Kotov et al., 1999).

\begin{tabular}{|l|c|c|c|}
\hline \multicolumn{1}{|c|}{ Mutation } & Nef cleavage & $\begin{array}{c}\text { Infectivity } \\
\text { reduction (\%) }\end{array}$ & Literature \\
\hline W57A & Yes * & 70 & $\begin{array}{c}\text { (Miller et al., 1997) } \\
\text { (Chen et al., 1998) }\end{array}$ \\
\hline L58A & Yes & 50 & (Chen et al., 1998) \\
\hline WL57GG & No & 75 & (Miller et al., 1997) \\
\hline WL57AA & No & 50 & $\begin{array}{c}\text { (Chen et al., 1998) } \\
\text { (Miller et al., 1997) }\end{array}$ \\
\hline CAW (55-57) LLL & Yes ** & 75 & (Miller et al., 1997) \\
\hline$\triangle$ CAW (55-57) & No & 70 & (Miller et al., 1997) \\
(Fackler et al., 2006)
\end{tabular}

Table 1. Mutations within the cleavage site of Nef and its effect on viral infectivity* Less cleavage of the Nef protein was observed (Miller et al., 1997). ${ }^{* *}$ A higher cleavage rate of the Nef protein was observed (Miller et al., 1997). ${ }^{* *}$ A cleavage site (ATIM) from the viral Nucleocapsid protein was introduced at amino acid position 55 in Nef, accelerated cleavage of Nef was observed (Pandori et al., 1998).

\section{Conclusion}

Nef is a multifunctional accessory protein only present in the primate lentiviruses. Its influence on viral infectivity and pathogenesis is undisputable. However, the mechanism by which Nef contributes to the optimal infectivity of these viruses is still a matter of controversy. The classical functions described for Nef are the downmodulation of the CD4 and MHC-I molecules from the cell surface and the activation of signaling cascades in Nefexpressing or HIV/SIV-infected cells. While the downmodulation of immune system molecules from the surface of cells, as described here, could all contribute to the effect of Nef on pathogenesis and disease progression, these functions failed to be correlated with the contribution of Nef to the optimal infectivity of HIV/SIV. Some experimental evidences 
prompt to the conclusion that Nef participates in an early step of the replication cycle postentry and before reverse transcription to increase infectivity. However it is becoming more evident that the requirement for Nef occurs in the producer cell, possibly by modifying or regulating the last steps of the viral replication cycle (assembly, budding and/or maturation) Nef would promote the formation of optimally infectious virus progeny.

In our model, the specific interaction of Nef with the precursor polyprotein GagPol and its influence on the kinetics of processing of the viral precursor proteins, predicts that in the absence of Nef viral PR will be activated earlier on during budding resulting in the incorporation of lower amounts of the viral enzymes into viral cores, especially IN. Since IN is crucial to the initiation of reverse transcription and that Nef-deleted viruses have a defect in viral DNA synthesis, our model conciliates these findings to explain the optimal infectivity of the viral particles in the presence of Nef.

If that is the case, very important implications for this function of Nef in the current antiretroviral therapy can be predicted. First, Nef could become a target to anti-retroviral drugs that would act in synergism with PR inhibitors currently in use to achieve a more efficient inhibition of virus replication. Second, we should predict a co-evolution of both Nef and PR during the therapy with PR inhibitors, which will have a direct impact on the selection of resistance mutations that is still not appreciated.

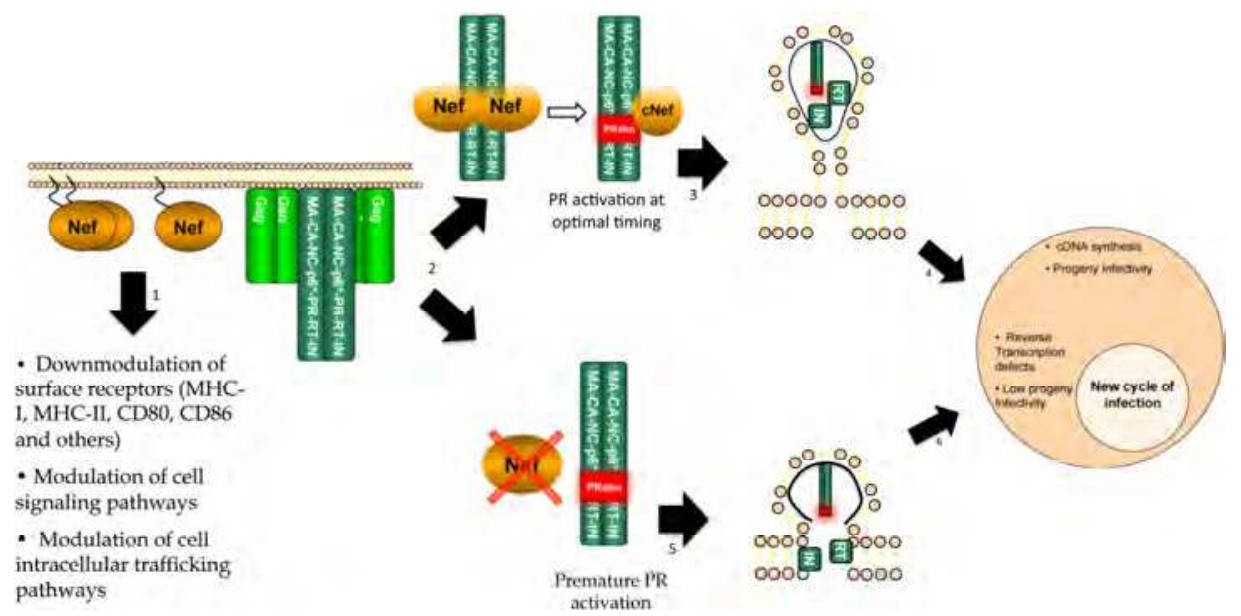

Fig. 2. Schematic representation of the working model for the functions of Nef during the last steps of the primate Lentiviral replication cycle. Nef associates with cellular membranes and classically exerts several functions that do not necessarily correlate with its role in increasing viral infectivity and promote disease progression (arrow 1). Nef from both HIV-1 and SIVmac binds to the p6*PR within the GagPol precursor (Costa et al., 2004; Jesus da Costa et al., 2009) (arrow 2). In the presence of Nef the viral PR is activated at an optimal time during the budding step, assuring the correct amount of the viral IN and RT inside the viral core (arrow 3). IN influences the activity of RT during the initiation of reverse transcription, therefore the normal amounst of IN in viral particles will promote optimal cDNA synthesis and viral infectivity of the incoming viruses (arrow 4). On the other hand, in the absence of Nef viral PR is prematurely activated, consequently the processing of the GagPol precursor would occur before the formation of the viral cores leading to a lesser incorporation of IN (arrow 5), what would impact reverse transcription and viral infectivity (arrow 6). 


\section{References}

Adachi, A., Ono, N., Sakai, H., Ogawa, K., Shibata, R., Kiyomasu, T., Masuike, H., Ueda, S., 1991. Generation and characterization of the human immunodeficiency virus type 1 mutants. Arch Virol 117, 45-58.

Aguiar, R.S., Peterlin, B.M., 2008. APOBEC3 proteins and reverse transcription. Virus research 134, 74-85.

Ahmad, N., Venkatesan, S., 1988. Nef protein of HIV-1 is a transcriptional repressor of HIV1 LTR. Science 241, 1481-1485.

Aiken, C., 1997. Pseudotyping human immunodeficiency virus type 1 (HIV-1) by the glycoprotein of vesicular stomatitis virus targets HIV-1 entry to an endocytic pathway and suppresses both the requirement for Nef and the sensitivity to cyclosporin A. J Virol 71, 5871-5877.

Aiken, C., Konner, J., Landau, N.R., Lenburg, M.E., Trono, D., 1994. Nef induces CD4 endocytosis: requirement for a critical dileucine motif in the membrane-proximal CD4 cytoplasmic domain. Cell 76, 853-864.

Aiken, C., Trono, D., 1995. Nef stimulates human immunodeficiency virus type 1 proviral DNA synthesis. J Virol 69, 5048-5056.

Alcover, A., Alarcon, B., 2000. Internalization and intracellular fate of TCR-CD3 complexes. Crit Rev Immunol 20, 325-346.

Alessandrini, L., Santarcangelo, A.C., Olivetta, E., Ferrantelli, F., d'Aloja, P., Pugliese, K., Pelosi, E., Chelucci, C., Mattia, G., Peschle, C., Verani, P., Federico, M., 2000. Ttropic human immunodeficiency virus (HIV) type 1 Nef protein enters human monocyte-macrophages and induces resistance to HIV replication: a possible mechanism of HIV T-tropic emergence in AIDS. J Gen Virol 81, 2905-2917.

Alexander, L., Du, Z., Howe, A.Y., Czajak, S., Desrosiers, R.C., 1999. Induction of AIDS in rhesus monkeys by a recombinant simian immunodeficiency virus expressing nef of human immunodeficiency virus type 1. J Virol 73, 5814-5825.

Arhel, N., 2010. Revisiting HIV-1 uncoating. Retrovirology 7, 96.

Arold, S., O'Brien, R., Franken, P., Strub, M.P., Hoh, F., Dumas, C., Ladbury, J.E., 1998. RT loop flexibility enhances the specificity of Src family SH3 domains for HIV-1 Nef. Biochemistry 37, 14683-14691.

Atkins, K.M., Thomas, L., Youker, R.T., Harriff, M.J., Pissani, F., You, H., Thomas, G., 2008. HIV-1 Nef binds PACS-2 to assemble a multikinase cascade that triggers major histocompatibility complex class I (MHC-I) down-regulation: analysis using short interfering RNA and knock-out mice. J Biol Chem 283, 11772-11784.

Baur, A.S., Sass, G., Laffert, B., Willbold, D., Cheng-Mayer, C., Peterlin, B.M., 1997. The Nterminus of Nef from HIV-1/SIV associates with a protein complex containing Lck and a serine kinase. Immunity 6, 283-291.

Bell, I., Ashman, C., Maughan, J., Hooker, E., Cook, F., Reinhart, T.A., 1998. Association of simian immunodeficiency virus Nef with the T-cell receptor (TCR) zeta chain leads to TCR down-modulation. J Gen Virol 79 ( Pt 11), 2717-2727.

Bentham, M., Mazaleyrat, S., Harris, M., 2003. The di-leucine motif in the cytoplasmic tail of CD4 is not required for binding to human immunodeficiency virus type 1 Nef, but is critical for CD4 down-modulation. J Gen Virol 84, 2705-2713. 
Blagoveshchenskaya, A.D., Thomas, L., Feliciangeli, S.F., Hung, C.H., Thomas, G., 2002. HIV-1 Nef downregulates MHC-I by a PACS-1- and PI3K-regulated ARF6 endocytic pathway. Cell 111, 853-866.

Blasius, A.L., Giurisato, E., Cella, M., Schreiber, R.D., Shaw, A.S., Colonna, M., 2006. Bone marrow stromal cell antigen 2 is a specific marker of type I IFN-producing cells in the naive mouse, but a promiscuous cell surface antigen following IFN stimulation. J Immunol 177, 3260-3265.

Bour, S., Schubert, U., Peden, K., Strebel, K., 1996. The envelope glycoprotein of human immunodeficiency virus type 2 enhances viral particle release: a Vpu-like factor? J Virol 70, 820-829.

Bresnahan, P.A., Yonemoto, W., Ferrell, S., Williams-Herman, D., Geleziunas, R., Greene, W.C., 1998. A dileucine motif in HIV-1 Nef acts as an internalization signal for CD4 downregulation and binds the AP-1 clathrin adaptor. Curr Biol 8, 1235-1238.

Breuer, S., Gerlach, H., Kolaric, B., Urbanke, C., Opitz, N., Geyer, M., 2006. Biochemical indication for myristoylation-dependent conformational changes in HIV-1 Nef. Biochemistry 45, 2339-2349.

Brun, S., Solignat, M., Gay, B., Bernard, E., Chaloin, L., Fenard, D., Devaux, C., Chazal, N., Briant, L., 2008. VSV-G pseudotyping rescues HIV-1 CA mutations that impair core assembly or stability. Retrovirology $5,57$.

Bukovsky, A., G^ttlinger, H., 1996. Lack of integrase can markedly affect human immunodeficiency virus type 1 particle production in the presence of an active viral protease. J Virol 70, 6820-6825.

Campbell EM, N.R., Hope TJ, 2004. Disruption of the actin cytoskeleton can complement the ability of Nef to enhance human immunodeficiency virus type 1 infectivity. J Virol $78,5745-5755$.

Campbell, E.M., Nunez, R., Hope, T.J., 2004. Disruption of the actin cytoskeleton can complement the ability of Nef to enhance human immunodeficiency virus type 1 infectivity. J Virol 78, 5745-5755.

Carl, S., Greenough, T.C., Krumbiegel, M., Greenberg, M., Skowronski, J., Sullivan, J.L., Kirchhoff, F., 2001. Modulation of different human immunodeficiency virus type 1 Nef functions during progression to AIDS. J Virol 75, 3657-3665.

Cavrois, M., Neidleman, J., Yonemoto, W., Fenard, D., Greene, W.C., 2004. HIV-1 virion fusion assay: uncoating not required and no effect of Nef on fusion. Virology 328, 36-44.

Chaudhry, A., Das, S.R., Hussain, A., Mayor, S., George, A., Bal, V., Jameel, S., Rath, S., 2005. The Nef protein of HIV-1 induces loss of cell surface costimulatory molecules CD80 and CD86 in APCs. J Immunol 175, 4566-4574.

Chaudhry, A., Verghese, D.A., Das, S.R., Jameel, S., George, A., Bal, V., Mayor, S., Rath, S., 2009. HIV-1 Nef promotes endocytosis of cell surface MHC class II molecules via a constitutive pathway. J Immunol 183, 2415-2424.

Chaudhuri, R., Lindwasser, O.W., Smith, W.J., Hurley, J.H., Bonifacino, J.S., 2007. Downregulation of CD4 by human immunodeficiency virus type 1 Nef is dependent on clathrin and involves direct interaction of Nef with the AP2 clathrin adaptor. J Virol 81, 3877-3890. 
Chazal, N., Singer, G., Aiken, C., Hammarskjold, M.L., Rekosh, D., 2001. Human immunodeficiency virus type 1 particles pseudotyped with envelope proteins that fuse at low $\mathrm{pH}$ no longer require Nef for optimal infectivity. J Virol 75, 4014-4018.

Chen, Y.L., Trono, D., Camaur, D., 1998. The proteolytic cleavage of human immunodeficiency virus type 1 Nef does not correlate with its ability to stimulate virion infectivity. J Virol 72, 3178-3184.

Cheng, H., Hoxie, J.P., Parks, W.P., 1999. The conserved core of human immunodeficiency virus type $1 \mathrm{Nef}$ is essential for association with Lck and for enhanced viral replication in T-lymphocytes. Virology 264, 5-15.

Cheng-Mayer, C., Iannello, P., Shaw, K., Luciw, P.A., Levy, J.A., 1989. Differential effects of nef on HIV replication: implications for viral pathogenesis in the host. Science 246, 1629-1632.

Chowers, M.Y., Pandori, M.W., Spina, C.A., Richman, D.D., Guatelli, J.C., 1995. The growth advantage conferred by HIV-1 nef is determined at the level of viral DNA formation and is independent of CD4 downregulation. Virology 212, 451-457.

Chukkapalli, V., Oh, S.J., Ono, A., 2010. Opposing mechanisms involving RNA and lipids regulate HIV-1 Gag membrane binding through the highly basic region of the matrix domain. Proc Natl Acad Sci U S A 107, 1600-1605.

Cortes, M.J., Wong-Staal, F., Lama, J., 2002. Cell surface CD4 interferes with the infectivity of HIV-1 particles released from T cells. J Biol Chem 277, 1770-1779.

Costa, L.J., Chen, N., Lopes, A., Aguiar, R.S., Tanuri, A., Plemenitas, A., Peterlin, B.M., 2006. Interactions between Nef and AIP1 proliferate multivesicular bodies and facilitate egress of HIV-1. Retrovirology 3, 33.

Costa, L.J., Zheng, Y.H., Sabotic, J., Mak, J., Fackler, O.T., Peterlin, B.M., 2004. Nef binds p6* in GagPol during replication of human immunodeficiency virus type 1. J Virol 78, 5311-5323.

Crotti, A., Neri, F., Corti, D., Ghezzi, S., Heltai, S., Baur, A., Poli, G., Santagostino, E., Vicenzi, E., 2006. Nef alleles from human immunodeficiency virus type 1-infected long-term-nonprogressor hemophiliacs with or without late disease progression are defective in enhancing virus replication and CD4 down-regulation. J Virol 80, 10663-10674.

Daniel, M.D., Kirchhoff, F., Czajak, S.C., Sehgal, P.K., Desrosiers, R.C., 1992. Protective effects of a live attenuated SIV vaccine with a deletion in the nef gene. Science 258, 1938-1941.

Daniel, M.D., Letvin, N.L., King, N.W., Kannagi, M., Sehgal, P.K., Hunt, R.D., Kanki, P.J., Essex, M., Desrosiers, R.C., 1985. Isolation of T-cell tropic HTLV-III-like retrovirus from macaques. Science 228, 1201-1204.

Deacon, N.J., Tsykin, A., Solomon, A., Smith, K., Ludford-Menting, M., Hooker, D.J., McPhee, D.A., Greenway, A.L., Ellett, A., Chatfield, C., Lawson, V.A., Crowe, S., Maerz, A., Sonza, S., Learmont, J., Sullivan, J.S., Cunningham, A., Dwyer, D., Dowton, D., Mills, J., 1995. Genomic structure of an attenuated quasi species of HIV-1 from a blood transfusion donor and recipients. Science 270, 988-991.

DeGottardi, M.Q., Specht, A., Metcalf, B., Kaur, A., Kirchhoff, F., Evans, D.T., 2008. Selective downregulation of rhesus macaque and sooty mangabey major histocompatibility complex class I molecules by Nef alleles of simian immunodeficiency virus and human immunodeficiency virus type 2. J Virol 82, 3139-3146. 
Dennis, C.A., Baron, A., Grossmann, J.G., Mazaleyrat, S., Harris, M., Jaeger, J., 2005. Cotranslational myristoylation alters the quaternary structure of HIV-1 Nef in solution. Proteins 60, 658-669.

Dikeakos, J.D., Atkins, K.M., Thomas, L., Emert-Sedlak, L., Byeon, I.J., Jung, J., Ahn, J., Wortman, M.D., Kukull, B., Saito, M., Koizumi, H., Williamson, D.M., Hiyoshi, M., Barklis, E., Takiguchi, M., Suzu, S., Gronenborn, A.M., Smithgall, T.E., Thomas, G., 2010. Small molecule inhibition of HIV-1-induced MHC-I down-regulation identifies a temporally regulated switch in Nef action. Mol Biol Cell 21, 3279-3292.

Djordjevic, J.T., Schibeci, S.D., Stewart, G.J., Williamson, P., 2004. HIV type 1 Nef increases the association of $\mathrm{T}$ cell receptor (TCR)-signaling molecules with $\mathrm{T}$ cell rafts and promotes activation-induced raft fusion. AIDS Res Hum Retroviruses 20, 547-555.

Dobard, C.W., Briones, M.S., Chow, S.A., 2007. Molecular mechanisms by which human immunodeficiency virus type 1 integrase stimulates the early steps of reverse transcription. J Virol 81, 10037-10046.

Douglas, J.L., Viswanathan, K., McCarroll, M.N., Gustin, J.K., Fruh, K., Moses, A.V., 2009. $\mathrm{Vpu}$ directs the degradation of the human immunodeficiency virus restriction factor BST-2/Tetherin via a beta\}TrCP-dependent mechanism. J Virol 83, 79317947.

Fackler, O.T., d'Aloja, P., Baur, A.S., Federico, M., Peterlin, B.M., 2001. Nef from human immunodeficiency virus type 1(F12) inhibits viral production and infectivity. J Virol 75, 6601-6608.

Fackler, O.T., Kienzle, N., Kremmer, E., Boese, A., Schramm, B., Klimkait, T., K,cherer, C., Mueller-Lantzsch, N., 1997. Association of human immunodeficiency virus Nef protein with actin is myristoylation dependent and influences its subcellular localization. Eur J Biochem 247, 843-851.

Fackler, O.T., Krausslich, H.G., 2006. Interactions of human retroviruses with the host cell cytoskeleton. Curr Opin Microbiol 9, 409-415.

Fackler, O.T., Luo, W., Geyer, M., Alberts, A.S., Peterlin, B.M., 1999. Activation of Vav by Nef induces cytoskeletal rearrangements and downstream effector functions. Mol Cell 3, 729-739.

Fackler, O.T., Moris, A., Tibroni, N., Giese, S.I., Glass, B., Schwartz, O., Krausslich, H.G., 2006. Functional characterization of HIV-1 Nef mutants in the context of viral infection. Virology 351, 322-339.

Fenard, D., Yonemoto, W., de Noronha, C., Cavrois, M., Williams, S.A., Greene, W.C., 2005. Nef is physically recruited into the immunological synapse and potentiates $\mathrm{T}$ cell activation early after TCR engagement. J Immunol 175, 6050-6057.

Forshey, B.M., Aiken, C., 2003. Disassembly of human immunodeficiency virus type 1 cores in vitro reveals association of Nef with the subviral ribonucleoprotein complex. J Virol 77, 4409-4414.

Forshey, B.M., von Schwedler, U., Sundquist, W.I., Aiken, C., 2002. Formation of a human immunodeficiency virus type 1 core of optimal stability is crucial for viral replication. J Virol 76, 5667-5677.

Fortin, J.F., Barat, C., Beausejour, Y., Barbeau, B., Tremblay, M.J., 2004. Hyperresponsiveness to stimulation of human immunodeficiency virus-infected CD4+ T cells requires Nef and Tat virus gene products and results from higher NFAT, NFkappaB, and AP-1 induction. J Biol Chem 279, 39520-39531. 
Foster, J.L., Garcia, J.V., 2008. HIV-1 Nef: at the crossroads. Retrovirology 5, 84.

Foti, M., Mangasarian, A., Piguet, V., Lew, D.P., Krause, K.H., Trono, D., Carpentier, J.L., 1997. Nef-mediated clathrin-coated pit formation. J Cell Biol 139, 37-47.

Frankel, A.D., Young, J.A., 1998. HIV-1: fifteen proteins and an RNA. Annu Rev Biochem 67, 1-25.

Freed, E.O., Mouland, A.J., 2006. The cell biology of HIV-1 and other retroviruses. Retrovirology 3, 77.

Freund, J., Kellner, R., Houthaeve, T., Kalbitzer, H.R., 1994. Stability and proteolytic domains of Nef protein from human immunodeficiency virus (HIV) type 1. Eur J Biochem 221, 811-819.

Fujii, K., Hurley, J.H., Freed, E.O., 2007. Beyond Tsg101: the role of Alix in 'ESCRTing' HIV1. Nat Rev Microbiol 5, 912-916.

Fujii, Y., Otake, K., Tashiro, M., Adachi, A., 1996. Soluble Nef antigen of HIV-1 is cytotoxic for human CD4+ T cells. FEBS Lett 393, 93-96.

Garcia, J.V., Miller, A.D., 1991. Serine phosphorylation-independent downregulation of cellsurface CD4 by nef. Nature 350, 508-511.

Garrus, J.E., von Schwedler, U.K., Pornillos, O.W., Morham, S.G., Zavitz, K.H., Wang, H.E., Wettstein, D.A., Stray, K.M., CÙtÈ, M., Rich, R.L., Myszka, D.G., Sundquist, W.I., 2001. Tsg101 and the vacuolar protein sorting pathway are essential for HIV-1 budding. Cell 107, 55-65.

Gatlin, J., Arrigo, S.J., Schmidt, M.G., 1998. HIV-1 protease regulation: the role of the major homology region and adjacent C-terminal capsid sequences. J Biomed Sci 5, 305308.

Gerdes, H.H., Bukoreshtliev, N.V., Barroso, J.F., 2007. Tunneling nanotubes: a new route for the exchange of components between animal cells. FEBS Lett 581, 2194-2201.

Geyer, M., Fackler, O.T., Peterlin, B.M., 2001. Structure--function relationships in HIV-1 Nef. EMBO Rep 2, 580-585.

Giorgi, J.V., Hausner, M.A., Hultin, L.E., 1999. Detailed immunophenotype of CD8+ memory cytotoxic T-lymphocytes (CTL) against HIV-1 with respect to expression of CD45RA/RO, CD62L and CD28 antigens. Immunol Lett 66, 105-110.

Goldsmith, M.A., Warmerdam, M.T., Atchison, R.E., Miller, M.D., Greene, W.C., 1995. Dissociation of the CD4 downregulation and viral infectivity enhancement functions of human immunodeficiency virus type 1 Nef. J Virol 69, 4112-4121.

Goto, T., Kennel, S.J., Abe, M., Takishita, M., Kosaka, M., Solomon, A., Saito, S., 1994. A novel membrane antigen selectively expressed on terminally differentiated human B cells. Blood 84, 1922-1930.

Gould, S.J., Booth, A.M., Hildreth, J.E., 2003. The Trojan exosome hypothesis. Proc Natl Acad Sci U S A 100, 10592-10597.

Greenberg, M., DeTulleo, L., Rapoport, I., Skowronski, J., Kirchhausen, T., 1998a. A dileucine motif in HIV-1 Nef is essential for sorting into clathrin-coated pits and for downregulation of CD4. Curr Biol 8, 1239-1242.

Greenberg, M.E., Iafrate, A.J., Skowronski, J., 1998b. The SH3 domain-binding surface and an acidic motif in HIV-1 Nef regulate trafficking of class I MHC complexes. Embo J $17,2777-2789$.

Greenway, A.L., McPhee, D.A., Allen, K., Johnstone, R., Holloway, G., Mills, J., Azad, A., Sankovich, S., Lambert, P., 2002. Human immunodeficiency virus type 1 Nef binds 
to tumor suppressor p53 and protects cells against p53-mediated apoptosis. J Virol 76, 2692-2702.

Gummuluru, S., Kinsey, C.M., Emerman, M., 2000. An in vitro rapid-turnover assay for human immunodeficiency virus type 1 replication selects for cell-to-cell spread of virus. J Virol 74, 10882-10891.

Gupta, R.K., Mlcochova, P., Pelchen-Matthews, A., Petit, S.J., Mattiuzzo, G., Pillay, D., Takeuchi, Y., Marsh, M., Towers, G.J., 2009. Simian immunodeficiency virus envelope glycoprotein counteracts tetherin/BST-2/CD317 by intracellular sequestration. Proc Natl Acad Sci U S A 106, 20889-20894.

Guy, C.S., Vignali, D.A., 2009. Organization of proximal signal initiation at the TCR:CD3 complex. Immunol Rev 232, 7-21.

Haller, C., Rauch, S., Michel, N., Hannemann, S., Lehmann, M.J., Keppler, O.T., Fackler, O.T., 2006. The HIV-1 pathogenicity factor Nef interferes with maturation of stimulatory T-lymphocyte contacts by modulation of N-Wasp activity. J Biol Chem 281, 19618-19630.

Hammes, S.R., Dixon, E.P., Malim, M.H., Cullen, B.R., Greene, W.C., 1989. Nef protein of human immunodeficiency virus type 1: evidence against its role as a transcriptional inhibitor. Proc Natl Acad Sci U S A 86, 9549-9553.

Hanna, Z., Kay, D.G., Rebai, N., Guimond, A., Jothy, S., Jolicoeur, P., 1998. Nef harbors a major determinant of pathogenicity for an AIDS-like disease induced by HIV-1 in transgenic mice. Cell 95, 163-175.

Hellen, C.U., de Crombrugghe, M., Wimmer, E., Seeger, M.A., Kaufman, T.C., 1989. Amalgamated sequences. Nature 340, 682.

Hinshaw, J.E., 2000. Dynamin and its role in membrane fission. Annu Rev Cell Dev Biol 16, 483-519.

Hodge, D.R., Dunn, K.J., Pei, G.K., Chakrabarty, M.K., Heidecker, G., Lautenberger, J.A., Samuel, K.P., 1998. Binding of c-Raf1 kinase to a conserved acidic sequence within the carboxyl-terminal region of the HIV-1 Nef protein. J Biol Chem 273, 1572715733.

Howe, A.Y., Jung, J.U., Desrosiers, R.C., 1998. Zeta chain of the T-cell receptor interacts with nef of simian immunodeficiency virus and human immunodeficiency virus type 2. J Virol 72, 9827-9834.

Hung, C.H., Thomas, L., Ruby, C.E., Atkins, K.M., Morris, N.P., Knight, Z.A., Scholz, I., Barklis, E., Weinberg, A.D., Shokat, K.M., Thomas, G., 2007. HIV-1 Nef assembles a Src family kinase-ZAP-70/Syk-PI3K cascade to downregulate cell-surface MHC-I. Cell Host Microbe 1, 121-133.

Iafrate, A.J., Carl, S., Bronson, S., Stahl-Hennig, C., Swigut, T., Skowronski, J., Kirchhoff, F., 2000. Disrupting surfaces of nef required for downregulation of CD4 and for enhancement of virion infectivity attenuates simian immunodeficiency virus replication in vivo. J Virol 74, 9836-9844.

Ishikawa, J., Kaisho, T., Tomizawa, H., Lee, B.O., Kobune, Y., Inazawa, J., Oritani, K., Itoh, M., Ochi, T., Ishihara, K., et al., 1995. Molecular cloning and chromosomal mapping of a bone marrow stromal cell surface gene, BST2, that may be involved in pre-Bcell growth. Genomics 26, 527-534. 
Janardhan, A., Swigut, T., Hill, B., Myers, M.P., Skowronski, J., 2004. HIV-1 Nef binds the DOCK2-ELMO1 complex to activate rac and inhibit lymphocyte chemotaxis. PLoS Biol 2, E6.

Jesus da Costa, L., Lopes Dos Santos, A., Mandic, R., Shaw, K., Santana de Aguiar, R., Tanuri, A., Luciw, P.A., Peterlin, B.M., 2009. Interactions between SIVNef, SIVGagPol and Alix correlate with viral replication and progression to AIDS in rhesus macaques. Virology 394, 47-56.

Jia, B., Serra-Moreno, R., Neidermyer, W., Rahmberg, A., Mackey, J., Fofana, I.B., Johnson, W.E., Westmoreland, S., Evans, D.T., 2009. Species-specific activity of SIV Nef and HIV-1 Vpu in overcoming restriction by tetherin/BST2. PLoS Pathog 5, e1000429.

Kaletsky, R.L., Francica, J.R., Agrawal-Gamse, C., Bates, P., 2009. Tetherin-mediated restriction of filovirus budding is antagonized by the Ebola glycoprotein. Proc Natl Acad Sci U S A 106, 2886-2891.

Kaminchik, J., Margalit, R., Yaish, S., Drummer, H., Amit, B., Sarver, N., Gorecki, M., Panet, A., 1994. Cellular distribution of HIV type 1 Nef protein: identification of domains in Nef required for association with membrane and detergent-insoluble cellular matrix. AIDS Res Hum Retroviruses 10, 1003-1010.

Kasper, M.R., Roeth, J.F., Williams, M., Filzen, T.M., Fleis, R.I., Collins, K.L., 2005. HIV-1 Nef disrupts antigen presentation early in the secretory pathway. J Biol Chem 280, 12840-12848.

Khan, M., Garcia-Barrio, M., Powell, M.D., 2001. Restoration of wild-type infectivity to human immunodeficiency virus type 1 strains lacking nef by intravirion reverse transcription. J Virol 75, 12081-12087.

Kim, S., Ikeuchi, K., Byrn, R., Groopman, J., Baltimore, D., 1989. Lack of a negative influence on viral growth by the nef gene of human immunodeficiency virus type 1 . Proc Natl Acad Sci U S A 86, 9544-9548.

Kirchhausen, T., 2000. Clathrin. Annu Rev Biochem 69, 699-727.

Kirchhoff, F., 2010. Immune evasion and counteraction of restriction factors by HIV-1 and other primate lentiviruses. Cell Host Microbe 8, 55-67.

Kirchhoff, F., Greenough, T.C., Brettler, D.B., Sullivan, J.L., Desrosiers, R.C., 1995. Brief report: absence of intact nef sequences in a long-term survivor with nonprogressive HIV-1 infection. N Engl J Med 332, 228-232.

Kirchhoff, F., Schindler, M., Specht, A., Arhel, N., Munch, J., 2008. Role of Nef in primate lentiviral immunopathogenesis. Cell Mol Life Sci 65, 2621-2636.

Kotov, A., Zhou, J., Flicker, P., Aiken, C., 1999. Association of Nef with the human immunodeficiency virus type 1 core. J Virol 73, 8824-8830.

Krausslich, H.G., Schneider, H., Zybarth, G., Carter, C.A., Wimmer, E., 1988. Processing of in vitro-synthesized gag precursor proteins of human immunodeficiency virus (HIV) type 1 by HIV proteinase generated in Escherichia coli. J Virol 62, 4393-4397.

Krautkramer, E., Giese, S.I., Gasteier, J.E., Muranyi, W., Fackler, O.T., 2004. Human immunodeficiency virus type 1 Nef activates p21-activated kinase via recruitment into lipid rafts. J Virol 78, 4085-4097.

Kupzig, S., Korolchuk, V., Rollason, R., Sugden, A., Wilde, A., Banting, G., 2003. Bst2/HM1.24 is a raft-associated apical membrane protein with an unusual topology. Traffic 4, 694-709. 
Laguette, N., Benichou, S., Basmaciogullari, S., 2009. Human immunodeficiency virus type 1 Nef incorporation into virions does not increase infectivity. J Virol 83, 1093-1104.

Lama, J., Mangasarian, A., Trono, D., 1999. Cell-surface expression of CD4 reduces HIV-1 infectivity by blocking Env incorporation in a Nef- and Vpu-inhibitable manner. Curr Biol 9, 622-631.

Lamers, S.L., Fogel, G.B., Huysentruyt, L.C., McGrath, M.S., 2010. HIV-1 nef protein visits Bcells via macrophage nanotubes: a mechanism for AIDS-related lymphoma pathogenesis? Curr HIV Res 8, 638-640.

Lang, S.M., Iafrate, A.J., Stahl-Hennig, C., Kuhn, E.M., Nisslein, T., Kaup, F.J., Haupt, M., Hunsmann, G., Skowronski, J., Kirchhoff, F., 1997. Association of simian immunodeficiency virus Nef with cellular serine/threonine kinases is dispensable for the development of AIDS in rhesus macaques. Nat Med 3, 860-865.

Lanier, L.L., 2005. Missing self, NK cells, and The White Album. J Immunol 174, 6565.

Le Guern, M., Levy, J.A., 1992. Human immunodeficiency virus (HIV) type 1 can superinfect HIV-2-infected cells: pseudotype virions produced with expanded cellular host range. Proc Natl Acad Sci U S A 89, 363-367.

Le Tortorec, A., Neil, S.J., 2009. Antagonism to and intracellular sequestration of human tetherin by the human immunodeficiency virus type 2 envelope glycoprotein. J Virol 83, 11966-11978.

Lee, C.M., Gala, S., Stewart, G.J., Williamson, P., 2008. The proline-rich region of HIV-1 Nef affects CXCR4-mediated chemotaxis in Jurkat T cells. Viral Immunol 21, 347-354.

Lindemann, D., Wilhelm, R., Renard, P., Althage, A., Zinkernagel, R., Mous, J., 1994. Severe immunodeficiency associated with a human immunodeficiency virus 1 NEF/3'long terminal repeat transgene. J Exp Med 179, 797-807.

Littman, D.R., 1987. The structure of the CD4 and CD8 genes. Annu Rev Immunol 5, 561584.

Lopez, L.A., Yang, S.J., Hauser, H., Exline, C.M., Haworth, K.G., Oldenburg, J., Cannon, P.M., 2010. Ebola virus glycoprotein counteracts BST-2/Tetherin restriction in a sequence-independent manner that does not require tetherin surface removal. J Virol 84, 7243-7255.

Louis, J.M., Weber, I.T., T^zsł̀r, J., Clore, G.M., Gronenborn, A.M., 2000. HIV-1 protease: maturation, enzyme specificity, and drug resistance. Adv Pharmacol 49, 111-146.

Lu, X., Wu, X., Plemenitas, A., Yu, H., Sawai, E.T., Abo, A., Peterlin, B.M., 1996. CDC42 and Rac1 are implicated in the activation of the Nef-associated kinase and replication of HIV-1. Curr Biol 6, 1677-1684.

Lu, X., Yu, H., Liu, S.H., Brodsky, F.M., Peterlin, B.M., 1998. Interactions between HIV1 Nef and vacuolar ATPase facilitate the internalization of CD4. Immunity 8, 647-656.

Luo, T., Douglas, J.L., Livingston, R.L., Garcia, J.V., 1998. Infectivity enhancement by HIV-1 Nef is dependent on the pathway of virus entry: implications for HIV-based gene transfer systems. Virology 241, 224-233.

Mahlknecht, U., Deng, C., Lu, M.C., Greenough, T.C., Sullivan, J.L., O'Brien, W.A., Herbein, G., 2000. Resistance to apoptosis in HIV-infected CD4+ T lymphocytes is mediated by macrophages: role for Nef and immune activation in viral persistence. J Immunol 165, 6437-6446.

Malim, M.H., Emerman, M., 2008. HIV-1 accessory proteins--ensuring viral survival in a hostile environment. Cell Host Microbe 3, 388-398. 
Mandic, R., Fackler, O.T., Geyer, M., Linnemann, T., Zheng, Y.H., Peterlin, B.M., 2001. Negative factor from SIV binds to the catalytic subunit of the V-ATPase to internalize CD4 and to increase viral infectivity. Mol Biol Cell 12, 463-473.

Mangasarian, A., Foti, M., Aiken, C., Chin, D., Carpentier, J.L., Trono, D., 1997. The HIV-1 Nef protein acts as a connector with sorting pathways in the Golgi and at the plasma membrane. Immunity 6, 67-77.

Mangino, G., Percario, Z.A., Fiorucci, G., Vaccari, G., Manrique, S., Romeo, G., Federico, M., Geyer, M., Affabris, E., 2007. In vitro treatment of human monocytes/macrophages with myristoylated recombinant Nef of human immunodeficiency virus type 1 leads to the activation of mitogen-activated protein kinases, IkappaB kinases, and interferon regulatory factor 3 and to the release of beta interferon. J Virol 81, 27772791.

Manninen, A., Saksela, K., 2002. HIV-1 Nef interacts with inositol trisphosphate receptor to activate calcium signaling in T cells. J Exp Med 195, 1023-1032.

Mansouri, M., Viswanathan, K., Douglas, J.L., Hines, J., Gustin, J., Moses, A.V., Fruh, K., 2009. Molecular mechanism of BST2/tetherin downregulation by K5/MIR2 of Kaposi's sarcoma-associated herpesvirus. J Virol 83, 9672-9681.

Mariani, R., Skowronski, J., 1993. CD4 down-regulation by nef alleles isolated from human immunodeficiency virus type 1-infected individuals. Proc Natl Acad Sci U S A 90, 5549-5553.

McNatt, M.W., Zang, T., Hatziioannou, T., Bartlett, M., Fofana, I.B., Johnson, W.E., Neil, S.J., Bieniasz, P.D., 2009. Species-specific activity of HIV-1 Vpu and positive selection of tetherin transmembrane domain variants. PLoS Pathog 5, e1000300.

Michel, N., Allespach, I., Venzke, S., Fackler, O.T., Keppler, O.T., 2005. The Nef protein of human immunodeficiency virus establishes superinfection immunity by a dual strategy to downregulate cell-surface CCR5 and CD4. Curr Biol 15, 714-723.

Miller, M.D., Warmerdam, M.T., Ferrell, S.S., Benitez, R., Greene, W.C., 1997. Intravirion generation of the C-terminal core domain of HIV-1 Nef by the HIV-1 protease is insufficient to enhance viral infectivity. Virology 234, 215-225.

Miller, M.D., Warmerdam, M.T., Page, K.A., Feinberg, M.B., Greene, W.C., 1995. Expression of the human immunodeficiency virus type 1 (HIV-1) nef gene during HIV-1 production increases progeny particle infectivity independently of gp160 or viral entry. J Virol 69, 579-584.

Mitchell, R.S., Chaudhuri, R., Lindwasser, O.W., Tanaka, K.A., Lau, D., Murillo, R., Bonifacino, J.S., Guatelli, J.C., 2008. Competition model for upregulation of the major histocompatibility complex class II-associated invariant chain by human immunodeficiency virus type 1 Nef. J Virol 82, 7758-7767.

Mitchell, R.S., Katsura, C., Skasko, M.A., Fitzpatrick, K., Lau, D., Ruiz, A., Stephens, E.B., Margottin-Goguet, F., Benarous, R., Guatelli, J.C., 2009. Vpu antagonizes BST-2mediated restriction of HIV-1 release via beta-TrCP and endo-lysosomal trafficking. PLoS Pathog 5, e1000450.

Nabel, G., Baltimore, D., 1987. An inducible transcription factor activates expression of human immunodeficiency virus in T cells. Nature 326, 711-713.

Navia, M.A., Fitzgerald, P.M., McKeever, B.M., Leu, C.T., Heimbach, J.C., Herber, W.K., Sigal, I.S., Darke, P.L., Springer, J.P., 1989. Three-dimensional structure of aspartyl protease from human immunodeficiency virus HIV-1. Nature 337, 615-620. 
Nayak, D.P., Hui, E.K., 2004. The role of lipid microdomains in virus biology. Subcell Biochem 37, 443-491.

Neil, S.J., Eastman, S.W., Jouvenet, N., Bieniasz, P.D., 2006. HIV-1 Vpu promotes release and prevents endocytosis of nascent retrovirus particles from the plasma membrane. PLoS Pathog 2, e39.

Neil, S.J., Sandrin, V., Sundquist, W.I., Bieniasz, P.D., 2007. An interferon-alpha-induced tethering mechanism inhibits HIV-1 and Ebola virus particle release but is counteracted by the HIV-1 Vpu protein. Cell Host Microbe 2, 193-203.

Neil, S.J., Zang, T., Bieniasz, P.D., 2008. Tetherin inhibits retrovirus release and is antagonized by HIV-1 Vpu. Nature 451, 425-430.

Niederman, T.M., Hastings, W.R., Ratner, L., 1993. Myristoylation-enhanced binding of the HIV-1 Nef protein to T cell skeletal matrix. Virology 197, 420-425.

Noviello, C.M., Pond, S.L., Lewis, M.J., Richman, D.D., Pillai, S.K., Yang, O.O., Little, S.J., Smith, D.M., Guatelli, J.C., 2007. Maintenance of Nef-mediated modulation of major histocompatibility complex class I and CD4 after sexual transmission of human immunodeficiency virus type 1. J Virol 81, 4776-4786.

Olivetta, E., Percario, Z., Fiorucci, G., Mattia, G., Schiavoni, I., Dennis, C., J\%oger, J., Harris, M., Romeo, G., Affabris, E., Federico, M., 2003. HIV-1 Nef induces the release of inflammatory factors from human monocyte/macrophages: involvement of Nef endocytotic signals and NF-kappa B activation. J Immunol 170, 1716-1727.

Olivetta, E., Pugliese, K., Bona, R., D'Aloja, P., Ferrantelli, F., Santarcangelo, A.C., Mattia, G., Verani, P., Federico, M., 2000. cis expression of the F12 human immunodeficiency virus (HIV) Nef allele transforms the highly productive NL4-3 HIV type 1 to a replication-defective strain: involvement of both Env gp41 and CD4 intracytoplasmic tails. J Virol 74, 483-492.

Pandori, M., Craig, H., Moutouh, L., Corbeil, J., Guatelli, J., 1998. Virological importance of the protease-cleavage site in human immunodeficiency virus type $1 \mathrm{Nef}$ is independent of both intravirion processing and CD4 down-regulation. Virology 251, 302-316.

Pandori, M.W., Fitch, N.J., Craig, H.M., Richman, D.D., Spina, C.A., Guatelli, J.C., 1996. Producer-cell modification of human immunodeficiency virus type 1: Nef is a virion protein. J Virol 70, 4283-4290.

Partin, K., Zybarth, G., Ehrlich, L., DeCrombrugghe, M., Wimmer, E., Carter, C., 1991. Deletion of sequences upstream of the proteinase improves the proteolytic processing of human immunodeficiency virus type 1. Proc Natl Acad Sci U S A 88, 4776-4780.

Percario, Z., Olivetta, E., Fiorucci, G., Mangino, G., Peretti, S., Romeo, G., Affabris, E., Federico, M., 2003. Human immunodeficiency virus type 1 (HIV-1) Nef activates STAT3 in primary human monocyte/macrophages through the release of soluble factors: involvement of Nef domains interacting with the cell endocytotic machinery. J Leukoc Biol 74, 821-832.

Percherancier, Y., Lagane, B., Planchenault, T., Staropoli, I., Altmeyer, R., Virelizier, J.L., Arenzana-Seisdedos, F., Hoessli, D.C., Bachelerie, F., 2003. HIV-1 entry into T-cells is not dependent on CD4 and CCR5 localization to sphingolipid-enriched, detergent-resistant, raft membrane domains. J Biol Chem 278, 3153-3161. 
Pettit, S.C., Clemente, J.C., Jeung, J.A., Dunn, B.M., Kaplan, A.H., 2005. Ordered processing of the human immunodeficiency virus type $1 \mathrm{GagPol}$ precursor is influenced by the context of the embedded viral protease. J Virol 79, 10601-10607.

Pettit, S.C., Everitt, L.E., Choudhury, S., Dunn, B.M., Kaplan, A.H., 2004. Initial cleavage of the human immunodeficiency virus type $1 \mathrm{GagPol}$ precursor by its activated protease occurs by an intramolecular mechanism. J Virol 78, 8477-8485.

Piguet, V., Chen, Y.L., Mangasarian, A., Foti, M., Carpentier, J.L., Trono, D., 1998. Mechanism of Nef-induced CD4 endocytosis: Nef connects CD4 with the mu chain of adaptor complexes. Embo J 17, 2472-2481.

Piguet, V., Gu, F., Foti, M., Demaurex, N., Gruenberg, J., Carpentier, J.L., Trono, D., 1999. Nef-induced CD4 degradation: a diacidic-based motif in Nef functions as a lysosomal targeting signal through the binding of beta-COP in endosomes. Cell 97, 63-73.

Pitcher, C., Honing, S., Fingerhut, A., Bowers, K., Marsh, M., 1999. Cluster of differentiation antigen 4 (CD4) endocytosis and adaptor complex binding require activation of the CD4 endocytosis signal by serine phosphorylation. Mol Biol Cell 10, 677-691.

Pizzato, M., Helander, A., Popova, E., Calistri, A., Zamborlini, A., Pal`, G., G’ttlinger, H.G., 2007. Dynamin 2 is required for the enhancement of HIV-1 infectivity by Nef. Proc Natl Acad Sci U S A 104, 6812-6817.

Pizzato, M., Popova, E., Gottlinger, H.G., 2008. Nef can enhance the infectivity of receptorpseudotyped human immunodeficiency virus type 1 particles. J Virol 82, 1081110819.

Popik, W., Alce, T.M., 2004. CD4 receptor localized to non-raft membrane microdomains supports HIV-1 entry. Identification of a novel raft localization marker in CD4. J Biol Chem 279, 704-712.

Popov, S., Strack, B., Sanchez-Merino, V., Popova, E., Rosin, H., G^ttlinger, H.G., 2011. Human Immunodeficiency Virus Type 1 and Related Primate Lentiviruses Engage Clathrin through Gag-Pol or Gag. J Virol 85, 3792-3801.

Qi, M., Aiken, C., 2008. Nef enhances HIV-1 infectivity via association with the virus assembly complex. Virology 373, 287-297.

Quaranta, M.G., Mattioli, B., Giordani, L., Viora, M., 2006. The immunoregulatory effects of HIV-1 Nef on dendritic cells and the pathogenesis of AIDS. FASEB J 20, 2198-2208.

Reid, P.A., Watts, C., 1992. Constitutive endocytosis and recycling of major histocompatibility complex class II glycoproteins in human B-lymphoblastoid cells. Immunology 77, 539-542.

Ritter, G.D., Jr., Yamshchikov, G., Cohen, S.J., Mulligan, M.J., 1996. Human immunodeficiency virus type 2 glycoprotein enhancement of particle budding: role of the cytoplasmic domain. J Virol 70, 2669-2673.

Roeth, J.F., Collins, K.L., 2006. Human immunodeficiency virus type 1 Nef: adapting to intracellular trafficking pathways. Microbiol Mol Biol Rev 70, 548-563.

Roeth, J.F., Williams, M., Kasper, M.R., Filzen, T.M., Collins, K.L., 2004. HIV-1 Nef disrupts MHC-I trafficking by recruiting AP-1 to the MHC-I cytoplasmic tail. J Cell Biol 167, 903-913.

Rollason, R., Korolchuk, V., Hamilton, C., Schu, P., Banting, G., 2007. Clathrin-mediated endocytosis of a lipid-raft-associated protein is mediated through a dual tyrosine motif. J Cell Sci 120, 3850-3858. 
Ross, T.M., Oran, A.E., Cullen, B.R., 1999. Inhibition of HIV-1 progeny virion release by cellsurface CD4 is relieved by expression of the viral Nef protein. Curr Biol 9, 613-621.

Rudolph, J.M., Eickel, N., Haller, C., Schindler, M., Fackler, O.T., 2009. Inhibition of T-cell receptor-induced actin remodeling and relocalization of Lck are evolutionarily conserved activities of lentiviral Nef proteins. J Virol 83, 11528-11539.

Saksela, K., Cheng, G., Baltimore, D., 1995. Proline-rich (PxxP) motifs in HIV-1 Nef bind to $\mathrm{SH} 3$ domains of a subset of Src kinases and are required for the enhanced growth of Nef+ viruses but not for down-regulation of CD4. Embo J 14, 484-491.

Sawai, E.T., Baur, A.S., Peterlin, B.M., Levy, J.A., Cheng-Mayer, C., 1995. A conserved domain and membrane targeting of Nef from HIV and SIV are required for association with a cellular serine kinase activity. J Biol Chem 270, 15307-15314.

Schindler, M., Munch, J., Brenner, M., Stahl-Hennig, C., Skowronski, J., Kirchhoff, F., 2004. Comprehensive analysis of nef functions selected in simian immunodeficiency virus-infected macaques. J Virol 78, 10588-10597.

Schindler, M., Munch, J., Kutsch, O., Li, H., Santiago, M.L., Bibollet-Ruche, F., MullerTrutwin, M.C., Novembre, F.J., Peeters, M., Courgnaud, V., Bailes, E., Roques, P., Sodora, D.L., Silvestri, G., Sharp, P.M., Hahn, B.H., Kirchhoff, F., 2006. Nefmediated suppression of $\mathrm{T}$ cell activation was lost in a lentiviral lineage that gave rise to HIV-1. Cell 125, 1055-1067.

Schindler, M., W sfl, S., Benaroch, P., Greenough, T.C., Daniels, R., Easterbrook, P., Brenner, M., Msnch, J., Kirchhoff, F., 2003. Down-modulation of mature major histocompatibility complex class II and up-regulation of invariant chain cell surface expression are well-conserved functions of human and simian immunodeficiency virus nef alleles. J Virol 77, 10548-10556.

Schmokel, J., Sauter, D., Schindler, M., Leendertz, F.H., Bailes, E., Dazza, M.C., Saragosti, S., Bibollet-Ruche, F., Peeters, M., Hahn, B.H., Kirchhoff, F., 2011. The presence of a vpu gene and the lack of Nef-mediated downmodulation of T cell receptor-CD3 are not always linked in primate lentiviruses. J Virol 85, 742-752.

Schorr, J., Kellner, R., Fackler, O., Freund, J., Konvalinka, J., Kienzle, N., Krausslich, H.G., Mueller-Lantzsch, N., Kalbitzer, H.R., 1996. Specific cleavage sites of Nef proteins from human immunodeficiency virus types 1 and 2 for the viral proteases. J Virol 70, 9051-9054.

Schubert, U., Anton, L.C., Bacik, I., Cox, J.H., Bour, S., Bennink, J.R., Orlowski, M., Strebel, K., Yewdell, J.W., 1998. CD4 glycoprotein degradation induced by human immunodeficiency virus type $1 \mathrm{Vpu}$ protein requires the function of proteasomes and the ubiquitin-conjugating pathway. J Virol 72, 2280-2288.

Schwartz, O., Marechal, V., Danos, O., Heard, J.M., 1995. Human immunodeficiency virus type 1 Nef increases the efficiency of reverse transcription in the infected cell. J Virol 69, 4053-4059.

Silvestri, G., Paiardini, M., Pandrea, I., Lederman, M.M., Sodora, D.L., 2007. Understanding the benign nature of SIV infection in natural hosts. J Clin Invest 117, 3148-3154.

Simmons, A., Aluvihare, V., McMichael, A., 2001. Nef triggers a transcriptional program in $\mathrm{T}$ cells imitating single-signal $\mathrm{T}$ cell activation and inducing HIV virulence mediators. Immunity 14, 763-777.

Simmons, A., Gangadharan, B., Hodges, A., Sharrocks, K., Prabhakar, S., Garcia, A., Dwek, R., Zitzmann, N., McMichael, A., 2005. Nef-mediated lipid raft exclusion of UbcH7 
inhibits $\mathrm{Cbl}$ activity in $\mathrm{T}$ cells to positively regulate signaling. Immunity $23,621-$ 634.

Skowronski, J., Parks, D., Mariani, R., 1993. Altered T cell activation and development in transgenic mice expressing the HIV-1 nef gene. Embo J 12, 703-713.

Sol-Foulon, N., Esnault, C., Percherancier, Y., Porrot, F., Metais-Cunha, P., Bachelerie, F., Schwartz, O., 2004. The effects of HIV-1 Nef on CD4 surface expression and viral infectivity in lymphoid cells are independent of rafts. J Biol Chem 279, 31398-31408.

Sousa, A.E., Carneiro, J., Meier-Schellersheim, M., Grossman, Z., Victorino, R.M., 2002. CD4 $\mathrm{T}$ cell depletion is linked directly to immune activation in the pathogenesis of HIV1 and HIV-2 but only indirectly to the viral load. J Immunol 169, 3400-3406.

Stolp, B., Abraham, L., Rudolph, J.M., Fackler, O.T., 2010. Lentiviral Nef proteins utilize PAK2-mediated deregulation of cofilin as a general strategy to interfere with actin remodeling. J Virol 84, 3935-3948.

Strack, B., Calistri, A., Craig, S., Popova, E., G^ttlinger, H.G., 2003. AIP1/ALIX is a binding partner for HIV-1 p6 and EIAV p9 functioning in virus budding. Cell 114, 689-699.

Stumptner-Cuvelette, P., Morchoisne, S., Dugast, M., Le Gall, S., Raposo, G., Schwartz, O., Benaroch, P., 2001. HIV-1 Nef impairs MHC class II antigen presentation and surface expression. Proc Natl Acad Sci U S A 98, 12144-12149.

Swann, S.A., Williams, M., Story, C.M., Bobbitt, K.R., Fleis, R., Collins, K.L., 2001. HIV-1 Nef blocks transport of MHC class I molecules to the cell surface via a PI 3-kinasedependent pathway. Virology 282, 267-277.

Swigut, T., Greenberg, M., Skowronski, J., 2003. Cooperative interactions of simian immunodeficiency virus Nef, AP-2, and CD3-zeta mediate the selective induction of T-cell receptor-CD3 endocytosis. J Virol 77, 8116-8126.

Swigut, T., Iafrate, A.J., Muench, J., Kirchhoff, F., Skowronski, J., 2000. Simian and human immunodeficiency virus Nef proteins use different surfaces to downregulate class I major histocompatibility complex antigen expression. J Virol 74, 5691-5701.

Swingler, S., Mann, A., Jacque, J., Brichacek, B., Sasseville, V.G., Williams, K., Lackner, A.A., Janoff, E.N., Wang, R., Fisher, D., Stevenson, M., 1999. HIV-1 Nef mediates lymphocyte chemotaxis and activation by infected macrophages. Nat Med 5, 997103.

Tang, J., Wong, R.N., 1987. Evolution in the structure and function of aspartic proteases. J Cell Biochem 33, 53-63.

Thoulouze, M.I., Sol-Foulon, N., Blanchet, F., Dautry-Varsat, A., Schwartz, O., Alcover, A., 2006. Human immunodeficiency virus type-1 infection impairs the formation of the immunological synapse. Immunity 24, 547-561.

Tobiume, M., Takahoko, M., Yamada, T., Tatsumi, M., Iwamoto, A., Matsuda, M., 2002. Inefficient enhancement of viral infectivity and CD4 downregulation by human immunodeficiency virus type 1 Nef from Japanese long-term nonprogressors. J Virol 76, 5959-5965.

Tobiume, M., Tokunaga, K., Kiyokawa, E., Takahoko, M., Mochizuki, N., Tatsumi, M., Matsuda, M., 2001. Requirement of nef for HIV-1 infectivity is biased by the expression levels of Env in the virus-producing cells and CD4 in the target cells. Arch Virol 146, 1739-1751.

Tripathi, P., Agrawal, S., 2007. The role of human leukocyte antigen E and G in HIV infection. Aids 21, 1395-1404. 
Van Damme, N., Goff, D., Katsura, C., Jorgenson, R.L., Mitchell, R., Johnson, M.C., Stephens, E.B., Guatelli, J., 2008. The interferon-induced protein BST-2 restricts HIV-1 release and is downregulated from the cell surface by the viral Vpu protein. Cell Host Microbe 3, 245-252.

VandeWoude, S., Apetrei, C., 2006. Going wild: lessons from naturally occurring Tlymphotropic lentiviruses. Clin Microbiol Rev 19, 728-762.

Varin, A., Manna, S.K., Quivy, V., Decrion, A.Z., Van Lint, C., Herbein, G., Aggarwal, B.B., 2003. Exogenous Nef protein activates NF-kappa B, AP-1, and c-Jun N-terminal kinase and stimulates HIV transcription in promonocytic cells. Role in AIDS pathogenesis. J Biol Chem 278, 2219-2227.

Vendrame, D., Sourisseau, M., Perrin, V., Schwartz, O., Mammano, F., 2009. Partial inhibition of human immunodeficiency virus replication by type I interferons: impact of cell-to-cell viral transfer. J Virol 83, 10527-10537.

Verkade, P., Simons, K., 1997. Robert Feulgen Lecture 1997. Lipid microdomains and membrane trafficking in mammalian cells. Histochem Cell Biol 108, 211-220.

von Schwedler, U.K., Stuchell, M., M,ller, B., Ward, D.M., Chung, H.Y., Morita, E., Wang, H.E., Davis, T., He, G.P., Cimbora, D.M., Scott, A., Kr\%ousslich, H.G., Kaplan, J., Morham, S.G., Sundquist, W.I., 2003. The protein network of HIV budding. Cell 114, 701-713.

Wang, C.Y., Mayo, M.W., Korneluk, R.G., Goeddel, D.V., Baldwin, A.S., 1998. NF-kappaB antiapoptosis: induction of TRAF1 and TRAF2 and c-IAP1 and c-IAP2 to suppress caspase-8 activation. Science 281, 1680-1683.

Wang JK, K.E., Verdin E, Trono D., 2000. The Nef protein of HIV-1 associates with rafts and primes T cells for activation. Proc Natl Acad Sci U S A 97, 394-399.

Wang, J.K., Kiyokawa, E., Verdin, E., Trono, D., 2000. The Nef protein of HIV-1 associates with rafts and primes T cells for activation. Proc Natl Acad Sci U S A 97, 394-399.

Warrilow, D., Tachedjian, G., Harrich, D., 2009. Maturation of the HIV reverse transcription complex: putting the jigsaw together. Rev Med Virol 19, 324-337.

Warrilow, D., Warren, K., Harrich, D., 2010. Strand transfer and elongation of HIV-1 reverse transcription is facilitated by cell factors in vitro. PLoS One 5, e13229.

Weber, I.T., 1990. Comparison of the crystal structures and intersubunit interactions of human immunodeficiency and Rous sarcoma virus proteases. J Biol Chem 265, 10492-10496.

Welker, R., Harris, M., Cardel, B., Kr\%ousslich, H.G., 1998. Virion incorporation of human immunodeficiency virus type 1 Nef is mediated by a bipartite membrane-targeting signal: analysis of its role in enhancement of viral infectivity. J Virol 72, 8833-8840.

Willey, R.L., Maldarelli, F., Martin, M.A., Strebel, K., 1992. Human immunodeficiency virus type 1 Vpu protein induces rapid degradation of CD4. J Virol 66, 7193-7200.

Wonderlich, E.R., Williams, M., Collins, K.L., 2008. The tyrosine binding pocket in the adaptor protein 1 (AP-1) mu1 subunit is necessary for Nef to recruit AP-1 to the major histocompatibility complex class I cytoplasmic tail. J Biol Chem 283, 30113022.

Wu, X., Liu, H., Xiao, H., Conway, J.A., Hehl, E., Kalpana, G.V., Prasad, V., Kappes, J.C., 1999. Human immunodeficiency virus type 1 integrase protein promotes reverse transcription through specific interactions with the nucleoprotein reverse transcription complex. J Virol 73, 2126-2135. 
Xu, W., Santini, P.A., Sullivan, J.S., He, B., Shan, M., Ball, S.C., Dyer, W.B., Ketas, T.J., Chadburn, A., Cohen-Gould, L., Knowles, D.M., Chiu, A., Sanders, R.W., Chen, K., Cerutti, A., 2009. HIV-1 evades virus-specific IgG2 and IgA responses by targeting systemic and intestinal B cells via long-range intercellular conduits. Nat Immunol 10, 1008-1017.

Xu, X.N., Laffert, B., Screaton, G.R., Kraft, M., Wolf, D., Kolanus, W., Mongkolsapay, J., McMichael, A.J., Baur, A.S., 1999. Induction of Fas ligand expression by HIV involves the interaction of Nef with the T cell receptor zeta chain. J Exp Med 189, 1489-1496.

Yang, S.J., Lopez, L.A., Hauser, H., Exline, C.M., Haworth, K.G., Cannon, P.M., 2010. Antitetherin activities in Vpu-expressing primate lentiviruses. Retrovirology 7, 13.

Yi, L., Rosales, T., Rose, J.J., Chowdhury, B., Knutson, J.R., Venkatesan, S., 2010. HIV-1 Nef binds a subpopulation of MHC-I throughout its trafficking itinerary and downregulates MHC-I by perturbing both anterograde and retrograde trafficking. J Biol Chem 285, 30884-30905.

Zhang, F., Wilson, S.J., Landford, W.C., Virgen, B., Gregory, D., Johnson, M.C., Munch, J., Kirchhoff, F., Bieniasz, P.D., Hatziioannou, T., 2009. Nef proteins from simian immunodeficiency viruses are tetherin antagonists. Cell Host Microbe 6, 54-67.

Zheng, Y.H., Plemenitas, A., Fielding, C.J., Peterlin, B.M., 2003. Nef increases the synthesis of and transports cholesterol to lipid rafts and HIV-1 progeny virions. Proc Natl Acad Sci U S A 100, 8460-8465. 


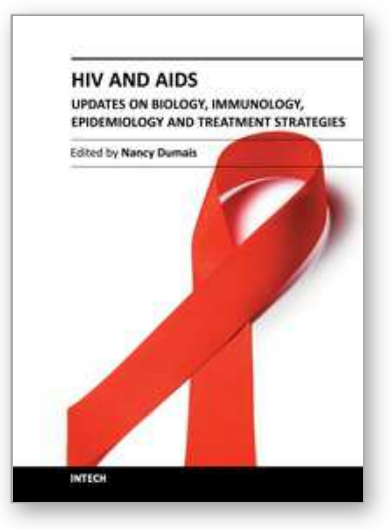

\section{HIV and AIDS - Updates on Biology, Immunology, Epidemiology and Treatment Strategies}

Edited by Dr. Nancy Dumais

ISBN 978-953-307-665-2

Hard cover, 694 pages

Publisher InTech

Published online 26, October, 2011

Published in print edition October, 2011

The continuing AIDS pandemic reminds us that despite the unrelenting quest for knowledge since the early 1980s, we have much to learn about HIV and AIDS. This terrible syndrome represents one of the greatest challenges for science and medicine. The purpose of this book is to aid clinicians, provide a source of inspiration for researchers, and serve as a guide for graduate students in their continued search for a cure of HIV. The first part of this book, â€œFrom the laboratory to the clinic,â€ and the second part, â€œFrom the clinic to the patients,â€ represent the unique but intertwined mission of this work: to provide basic and clinical knowledge on HIV/AIDS.

\section{How to reference}

In order to correctly reference this scholarly work, feel free to copy and paste the following:

Luciana J. Costa, Luiza M. Mendonça and Thatiane L. Sampaio (2011). Functions of the Lentiviral Accessory Protein Nef During the Distinct Steps of HIV and SIV Replication Cycle, HIV and AIDS - Updates on Biology, Immunology, Epidemiology and Treatment Strategies, Dr. Nancy Dumais (Ed.), ISBN: 978-953-307-665-2, InTech, Available from: http://www.intechopen.com/books/hiv-and-aids-updates-on-biology-immunologyepidemiology-and-treatment-strategies/functions-of-the-lentiviral-accessory-protein-nef-during-the-distinctsteps-of-hiv-and-siv-replicati

\section{INTECH}

open science | open minds

\author{
InTech Europe \\ University Campus STeP Ri \\ Slavka Krautzeka 83/A \\ 51000 Rijeka, Croatia \\ Phone: +385 (51) 770447 \\ Fax: +385 (51) 686166 \\ www.intechopen.com
}

\author{
InTech China \\ Unit 405, Office Block, Hotel Equatorial Shanghai \\ No.65, Yan An Road (West), Shanghai, 200040, China \\ 中国上海市延安西路65号上海国际贵都大饭店办公楼 405 单元 \\ Phone: +86-21-62489820 \\ Fax: +86-21-62489821
}


(C) 2011 The Author(s). Licensee IntechOpen. This is an open access article distributed under the terms of the Creative Commons Attribution 3.0 License, which permits unrestricted use, distribution, and reproduction in any medium, provided the original work is properly cited. 